Working Paper 01-23

Business Economics Series 08

March 2001
Departamento de Economía de la Empresa

Universidad Carlos III de Madrid

Calle Madrid, 126

28903 Getafe (Spain)

Fax (34-91) 6249608

\title{
OPTIMAL DEMAND FOR LONG-TERM BONDS WHEN RETURNS ARE PREDICTABLE ${ }^{1}$
}

\author{
Javier Gil-Bazo*
}

\section{Abstract}

This paper further explores the horizon effect in the optimal static and dynamic demand for risky assets under return predictability as documented by Barberis (2000). Contrary to the case of stocks, the optimal demand for long-term Government bonds of a buy-and-hold investor is not necessarily increasing in the investment horizon, and may in fact be decreasing for some initial levels of the predicting variable. The paper provides an analytical explanation based on the dependence of the mean variance ratio on the investor's time horizon. Under stationarity of the predicting variable, unusually high or unusually low levels of the predictor tend to dissapear over time inducing the mean of cumulative returns to grow less or more than linearly as the investment horizon increases. If this effect dominates that on the variance, optimal demands can either be increasing or decresing in the investment horizon. On the other hand, the solution to the investor's dynamic allocation problem in the presence of bonds indicates that long-term Government bonds do not provide a good hedge for adverse changes in the investor's opportunity set: optimal dynamic demands for bonds do not differ from static portfolio choices at any horizon.

\section{JEL Classification: G11, G12}

\footnotetext{
${ }^{1}$ Many thanks to Gonzalo Rubio, Manuel Moreno, Rafael Repullo, Ignacio Peña, David Musto, and José Marín for helpful comments and discussions. The paper was completed while the author was a Visiting PhD student at the Wharton School. Funding from the Spanish Government's Programa de Formación de Profesorado Universitario y Personal Investigador is gratefully acknowledged.

*Universidad Carlos III de Madrid. Departamento de Economía de la Empresa. C/ Madrid, 126, 28903 Getafe (Madrid), Spain. E-mail:jjgil@emp.uc3m.es. Tel.: +34-91-624.5844. Fax: +34-91-624.9608
} 


\section{Introduction}

Optimal portfolio selection is an old problem in Financial Economics. In a single-period context, mean variance analysis predicts that the optimal portfolio composition depends on the ..rst two moments of asset returns. In the presence of a risk free asset, investors will divide their investment betwen a portfolio of risky assets-identical for all investors- and the riskless asset. T he fraction of the total portfolio that each investor will allocate to the risky asset will depend on his or her attitude towards risk. However, making recommendations regarding optimal portfolio choice is not an easy task.

First of all, mean variance analy sis is consistent with expected utility maximization only under the assumption that the distribution of returns is multivariate normal or when the investor has quadratic preferences. But even under those circumstances, there do not exist analytic results that completely characterize the solution to the investor's asset allocation problem in every possible case.

Second, there is no direct relationship between predictability and optimal portfolio choice even under the most simple preference characterization (preferences de..ned over the mean and variance of the distribution of asset returns). $\mathrm{N}$ evertheless, optimal portfolio policy must take predictability into account since there exists a vast amount of empirical evidence in the literature that favors the time-varying conditional moments hypothesis. See for inst ance $\mathrm{C}$ ampbell (1987), C ampbell and Shiller (1988a, 1988b), Fama (1984), Fama (1990), Fama and French (1988, 1989), or Hodrick (1992).

Third, closed-form solutions to the dynamic portfolio problem faced by an investor with a general class of preferences are unknown when the investment opportunity set changes over time.

Finally, in the real world investors never know exactly the true value of the moments of the distribution of future returns and must therefore estimate them from past realizations. A $n$ investor that recognizes estimation risk must take it into account when deciding the composition of his portfolio.

Luckily, some recent contributions have addressed these diф culties in a straightforward way.

K andel and Stambaugh (1996) extend K lein and B awa's (1976) optimal portfolio analysis under parameter uncertainty to the context in which expected moments are not independently and identically distributed but can be predicted by a set of variables. The investor in their model is aware of asset return predictability but is ignorant about the true value of the return generating model parameters. Kandel and Stambaugh are able to characterize the single-period optimal demand using a numerical method and in a Bayesian framework. However, return predictability does not only axect its conditional distribution over any given number of periods ahead, but it also potentially introduces a horizon exect on the optimal portfolio choice. Albeit dixerent, that exect is closely related to the concept of intertemporal hedging demand, that is, the dixerence between the optimal demand for an asset by an investor with a long-term horizon and the demand by a myopic investor. Intertemporal hedging demand is dixer- 
ent from zero whenever investment opportunities are time-varying ${ }^{1}$. If returns are however not identically and independently distributed (i.i.d.), part of an investor's position is explained by his desire to hedge fut ure aver se predictable changes (see M erton (1969, 1971, 1973) and Samuelson (1969)). Similarly, the static demand (the demand of an investor who follows a buy-and-hold strategy) depends on the investment horizon when the conditional distribution of returns is time-varying. In this case, however, the reason is dixerent. When returns are not i.i.d., each period's return increases the mean and variance of the cumulative return up to that particular period in a dixerent proportion. As a consequence of the dixerent impact on each moment, the optimal portfolio choice that solves the investor's problem depends on his or her investment horizon.

The horizon exect on the optimal portfolio has been studied by Barberis ${ }^{2}$ (2000), who ..nds that when stock returns are predictable, the optimal investment in stocks is increasing in the investment horizon both with and without portfolio rebalancing. Barberis argues that predictability in stock expected returns induces mean reversion which in turn makes the variance of cumulative returns grow less than linearly as the horizon increases. As a result, a risk averse long-term invest or should allocate more to stocks than a short-term investor, independently of the initial value of the predicting variable. As for the case of an investor who periodically rebalances his portfolio Barberis' results suggest show that investors choose to hedge adverse changes in the investment opportunity set by investing more in stocks since realized returns and expected returns are negatively related. Nevertheless, when the investor takes estimation risk into account, the exect of the investment horizon on the optimal allocation may decrease and even become negative.

This paper st arts by exploring analytically the exect of predict ability on both the variance and the mean of cumulative returns. The main ..nding is that mean reversion does not necessarily induce a positive horizon exect on optimal asset allocation. Intuitively, when the predictive variable is stationary, its exect on the mean of cumulative returns decays with time. If the predicting variable has a positive exect on future expected returns, its dilution with time may oxset the positive horizon exect induced by mean reversion. The empirical analysis of the optimal static demand for long-term $\mathrm{G}$ overnment bonds con..rms the theor etical prediction: horizon exects may actually be eit her positive or negat ive depending on the initial value of the predicting variable(s) and, in any case, disappear as the investment horizon grows to in..nity. This study suggests that Barberis' (2000) results could be speci..c to the choice of the investable asset (a stock

\footnotetext{
${ }^{1}$ Except for the case of an investor with logarithmic preferences.

${ }^{2} \mathrm{~B}$ arberis' paper is part of a long series of recent contributions to the asset allocation literature. Brennan, Schwartz and Lagnado (1997) ..nd a numerical solution to the problem of a long-term investor who rebalances his portfol io frequently. They ..nd that long-t erm demand for both bonds and stocks is higher than that of a single-period investor. Balduzzi and Lynch (1999) emply an alter native numerical method to solve the intertemp oral consumption and portfol io choice in the presence of transaction costs. B randt (1999) estimates non parametrically the values of consumption and portfolio choice that solve $E$ uler's intertemporal equation. F inally, Campbell and V iceira (1999) obtain a log-linear approximation to the solution of the investor's dynamic problem.
} 
index) and the predicting variable (dividend yield) and not a consequence of return predictability or mean reversion.

Allowing for the presence of ..xed income -and more speci..cally Government debt- in the investor's portfolio choice problem not only illustrates the theoretical analysis of the relationship between predictability and investment horizon, but it is also particularly relevant given the important role that this kind of assets play in the investment industry. In the case of Spain, for instance, investment institutions manage 111 billion Eur os worth of ..xed income assets -53 per cent of total assets under management as opposed to 11 per cent invested in stocks- most of which (83 per cent) corresponds to Government debt ${ }^{3}$.

Next, the intertemporal hedging demand for long-term credit risk free bonds is studied for investors with dixerent investment horizons. The demand for long-term bonds has been previously analyzed by Campbell and Viceira (1998) through an approximate analytical solution to the dynamic problem ${ }^{4}$. Taking infation risk into account, they ...nd that the demand for long-term bonds is explained especially by hedging demand. Campbell and Viceira's (1998) model assumes that the investor has an in...nite horizon, however, when conditional moments are time-varying, the optimal portfolio choice of an investor with a ...nite horizon may in principle dixer to a great extent from that of an in..nitely lived investor. A s opposed to Campbell and Viceira (1998), the framework used in this paper makes it possible to analyze the exect of the investment horizon and the initial value of the predicting variables. The results suggest that in the absence of infation risk, the hedging demand for long-term bonds by invest ors with dixerent ..nite horizons is zero. In other words, investing in bonds does not provide a good hedge for changes in the predicting variable.

Finally, the paper studies optimal portfolio choice when both risky assets are available for investment. R esults show that:

1. changes in the initial values of the predictors alter the optimal portfolio choice for any given horizon,

2. the corresponding reallocation between dixerent assets also depends on the investment horizon, and

3. estimation risk axects the investor's position in stocks to a greater extent than his position in bonds.

The rest of the paper is divided in the following sections: section 2 presents the portfolio choice framework employed by B arberis (2000); section 3 presents the dataset employed for this research; section 4 deals with the static demand for long-term bonds in the absence of stocks, section 5 shows the results for the dynamic problem, section 6 explores the horizon exect on the optimal asset mix between long-term bonds and stocks; and ..nally section 7 concludes.

\footnotetext{
${ }^{3}$ Figures have been taken from the Spanish Security Market Committee report for the ..rst quarter of 1999 ("Informe trimestral de instituciones de inversión colectiva", Comisión $\mathrm{N}$ acional del M ercado de Valores).

4 The method was also used by Restoy (1992), Campbell (1993), and Campbell and Viceira (1999).
} 


\section{Optimal portfolio choice when returns are pre- dictable}

Consider the problem at time $T$ of an investor who derives utility from his wealth at time $T+\hat{T}$. The investor can invest his wealth in three dixerent assets: one-month Treasury Bills; a representative portfolio (index) of stocks; and a representative portfolio of $\mathrm{G}$ overnment Bonds with 10 years to maturity. The investor does not rebalance his portfolio. It will be assumed that the continuously compounded monthly real return on Treasury Bills, denoted by $r_{f}$ is constant. In order to compare results to those obtained by Barberis (2000), $r_{f}$ will also be taken to be 0:0036; or 4:32\% in annual terms. Returns in excess of the riskless interest rate on the stock index and the bond portfolio between periods $t_{i} 1$ and $t$ are denoted by $r_{s t}$ and $r_{\text {bt }}$ respectively.

If initial wealth equals one, $!_{s}$ stands for the fraction of the investor's initial wealth allocated to stocks, and $!_{\mathrm{b}}$ denotes the allocation to bonds, then the investor's terminal wealth is given by:

$W_{T+\hat{T}}=\left(1_{i} !_{s} i \quad !_{b}\right) \exp \left(r_{f} \hat{T}\right)+!_{s} \exp \left(r_{f} \hat{T}+R_{s ; T+\hat{T}}\right)+!_{b} \exp \left(r_{f} \hat{T}+R_{b ; T+\hat{T}}\right) ;$

where $R_{s ; T+T^{\prime}}$ and $R_{b ; T+\hat{T}}$ are cumulative excess returns between $T$ and $T+\hat{\uparrow}$ :

$$
\begin{aligned}
& R_{s ; T+\hat{T}}=r_{s ; T+1}+r_{s ; T+2}+\not \Phi 屯+r_{s ; T+\hat{T}} ; \\
& R_{b ; T+\hat{T}}=r_{b ; T+1}+r_{b ; T+2}+\not \Phi 屯+r_{b ; T+\hat{T}}:
\end{aligned}
$$

Investor's preferences can be represented by utility functions with constant relative risk aversion:

$$
\mathrm{u}(\mathrm{W})=\frac{\mathrm{W}^{1 \mathrm{i} A}}{1 \mathrm{i} A} ; \quad \text { with } A \in 1:
$$

The problem can then be formally stated as follows:

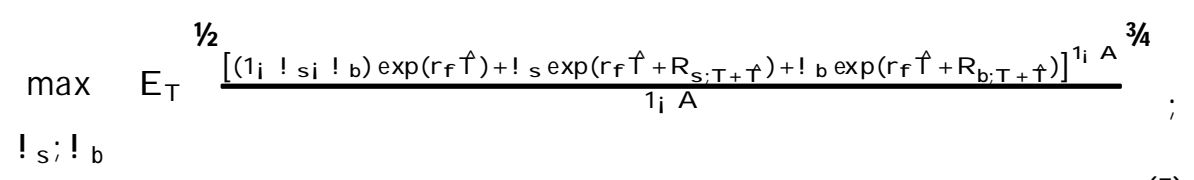

with portfolio weights constrained to be between zero and one.

A $s$ in Barberis (2000) the objective function is numerically evaluat ed as the integral: 


$$
\begin{aligned}
& \text { Z } \\
& u\left(W_{T+T}\right) p\left(R_{T+T^{\prime}} j \odot_{T}\right) d R_{T+T^{\prime}} ;
\end{aligned}
$$

where $R$ is the return vector $\left(R_{s} ; R_{b}\right)$ and $\Theta_{T}$ is the investor's information set at $T$.

In order to compute the integral (6), ..rst a large number of realizations of future returns are simulated from the distribution de..ned by $p\left(R_{T+\tau} j \Theta_{T}\right)$. $\mathrm{Next}$, for every simulated realization the value of the integral's argument is calculated and ..nally the arithmetic mean of all values is obtained. The solution to the optimization problem is the portfolio choice that maximizes the int egral's numeric value.

Therefore, we ..rst need to know the predictive distribution of fut ure returns. Excess returns are assumed to be generated by the following VAR model:

$$
z_{t}=a+B x_{t_{i} 1}+{ }^{2} t
$$

where $z_{t}^{0}=\left(r_{s t} ; r_{b t} ; x_{t}^{0}\right) ; x_{t}=\left(x_{1 t} ;:: ; x_{n t}\right){ }^{0}{ }^{a n d}{ }^{2} t$ is identically and independently distribut ed according to $N(0 ; \S)$. Vector $x_{t}$ is the vector of variables that predict expected returns. P rior to Barberis (2000), a similar VAR model has been used in the context of return prediction by Campbell (1991), and Hodrick (1992). It is useful to rewrite (7) as:

$$
z_{t}=a+B_{0} z_{t_{i} 1}+{ }^{2} t
$$

where:

$$
\mathrm{B}_{0}=\begin{array}{rrrrr}
20 & 0 & 0 & 1 & 3 \\
4 \mathrm{~B} & \vdots & \vdots & \AA & \mathrm{B} 5: \\
0 & 0
\end{array}
$$

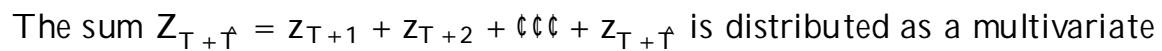
normal with mean ${ }^{1}$ sum and variance $\S$ sum given by:

$$
\begin{aligned}
& { }_{\text {sum }}=\hat{T a}+\left(\hat{T} \hat{i}_{1}\right) B_{0} a+(\hat{T} i 2) B_{0}^{2} a+\Phi \notin \Phi+B_{0}^{\hat{i_{i}}{ }^{1} a} \\
& +\left(B_{0} a+B_{0}^{2} a+\Phi \Phi 屯+B_{0}^{\hat{T}}\right) z_{T} ; \\
& \S_{\text {sum }}=\S \\
& +\left(I+B_{0}\right) \S\left(I+B_{0}\right)^{0} \\
& +\left(1+B_{0}+B_{0}^{2}\right) \S\left(I+B_{0}+B_{0}^{2}\right)^{0}
\end{aligned}
$$

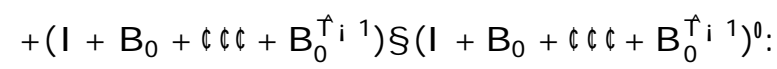


The investor could therefore est imate the parameters in (7) and take as the predictive distribution of returns a multivariate normal distribution with mean and variance ${ }^{r_{\text {sum }}}$ and $\hat{\S}_{\text {sum }}$; respectively. Simulating a large sample of returns, the invest or could evaluate (6). This strategy however does not take into account the fact that the investor does not know the true values of parameters in (7), denoted by $\mu$ On the other hand, if the invest or decides to take estimation risk into account, he will take as the predictive distribution that resulting from integrating the joint distribution of future returns and the parameters in (7). Namely, the investor will obtain the probability density function for returns as:

$$
\begin{aligned}
& p\left(R_{T+\uparrow^{\prime}} j \Theta_{T}\right)^{\prime} p\left(R_{T+\uparrow^{\prime}} j z\right) \quad R=R^{R}\left(R_{T+\uparrow} ; \mu j z\right) d \mu \\
& =p\left(R_{T+T} j \mu ; z\right) p(\mu j z) d \mu ;
\end{aligned}
$$

where $z=z_{1} ; z_{2} ; ;: ; z_{T}$. The probability density $p\left(R_{T+T^{\wedge}} j \mu ; z\right)$ corresponds to a multivariate normal distribution with mean and variance equal to ${ }^{1}$ sum and $\S$ sum. The density $p(\mu \mathrm{j} z)$ can be obtained in a Bayesian fashion:

$$
p(\mu j z) \_p(z j \mu) p(\mu):
$$

Intuitively, after observing the data set $z$; the investor learns the likelihood function $p(z j \mu)$ and will thus update his prior beliefs about the parameters - which can be summarized as the prior density $p(\mu)$ - giving rise to the posterior density $\mathrm{p}(\mu \mathrm{j} z)$ :

A $n$ investor who takes parameter uncertainty into account can therefore evaluate the following integral:

$$
\begin{aligned}
& \text { Z } \\
& u\left(W_{T+\uparrow^{\top}}\right) p\left(R_{T+\uparrow^{\prime}} j \mu ; z\right) p(\mu j z) d \mu d R_{T+T^{\prime}}:
\end{aligned}
$$

In practical terms, a realization of the vector $\mu$ is ..rst drawn from the posterior distribution and next a possible realization of $R_{T+T}$ is simulated using the distribution of future returns conditional on those parameter values.

The posterior distribution $\mathrm{p}(\mu \mathrm{j} z)$ when $\mathrm{z}=\mathrm{z}_{1} ; \mathrm{z}_{2} ; \cdots ; ; \mathrm{z}_{\mathrm{T}}$ is obtained as follows. First, the model can be written as:

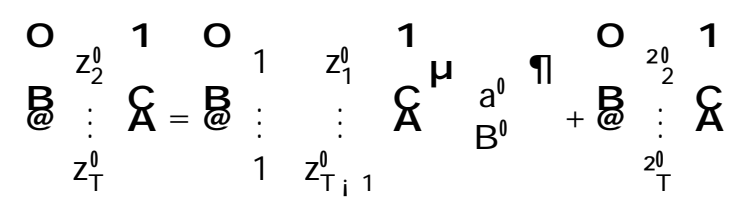

or equivalently:

$$
Z=X C+E ;
$$

where $Z$ is a $(T ; 1 ; n+2)$ matrix with vector $z_{2}^{0} ; \ldots ; ; Z_{T}^{0}$ as columns; $X$ is a $(T ; 1 ; n+1)$ matrix with vectors $\left(1 x_{1}^{0}\right) ; \ldots ; ;\left(1 x_{T_{i} 1}^{0}\right)$ as rows, and $E$ is a 
$\left(\mathrm{T} ; 1 ; \mathrm{n}+2\right.$ ) matrix with vectors ${ }_{2}^{20} ; \ldots ; ;{ }^{20}$ as rows. $M$ atrix $\mathrm{C}$ has dimension $(n+1 ; n+2)$ and contains row $a^{0}$ and matrix $B^{0}$ :

B arberis (2000) uses Zellner's (1971) Bayesian analysis of the multivariate regression model with exogenous regressors, given that the form of the likelihood function is the same when the distribution is conditioned on the sample's ..rst observation $z_{1}$. As in B arberis, it will be assumed that the investor has no previous information about the value of $\mu$ and hence a standard dixuse probability density is used:

$$
p(C ; \S) \_j \S j^{i} \frac{n+2}{2}:
$$

The resulting posterior distribution $p\left(C ; \S^{i^{1}} \mathrm{j} z\right)$ is given by:

$$
\begin{array}{rll}
\S^{i 1} & j & z \gg W i \operatorname{shart}\left(T ; n ; 2 ; S^{i 1}\right) \\
\operatorname{ved}(C) & j & \S ; z » N\left(\operatorname{ved}(\hat{C}) ; \S-\left(X X^{0}\right)^{i 1}\right)
\end{array}
$$

where $S=(Z ; \times \hat{C})^{0}(Z ; \times \hat{C})$ with $\hat{C}=\left(X{ }^{0} X\right)^{i}{ }^{1} \times{ }^{0}$. Every simulated realization of $(C ; \S)$ can be obtained by ..rst drawing from the marginal distribution of $\S^{i^{1}}$ and then drawing from the distribution of $C$ conditioned on $\S$ :

In particular, the size of the simulated sample is 100,000 in the case of no parameter uncertainty and 10,000 when estimation risk is taken into account.

\section{Data}

The stock market return is proxied by the return on the value-weighted index of the $\mathrm{N}$ ew Y ork Stock Exchange, and the return on long-term bonds is proxied by the return on a representative constant maturity portfolio of 10-year US Government Bonds. Data were obtained with a monthly frequency for the period covering J anuary 1959 to December 1998. In order to compute excess returns the series of returns on one-month Treasury Bills was also collected.

In order to predict expected returns on bonds and stocks, four variables are selected:

1. The default spread, proxied by the yield dixerence betwen Moody's Baa and $A$ aa rated corporate bonds.

2. The dividend yield on the stock index, computed as the sum of dividends payed on the index over the previous 12 months divided by the current index level. It is henceforth denoted by DP.

3. The term spread, proxied by the yield dixerence between 10-year and oneyear US G overnment B onds.

4. The trend of the stock index, de.ned as the dixerence between the logarithm of the index's current level and the average level over the previous 12 months. 
The default spread and theterm spread were obtained from the Inter net site maintained by the US Federal Reserve, whereas the rest of data were collected from the CR SP (C enter for Research in Security P rices) database.

These predictors have been previously used by Fama and French $(1988,1989)$ and Keim and Stambaugh (1986). Recently, Aït-Sahalia and B randt (2001) have used them to extend B randt's (1999) non paramet ric optimal portfolio estimation to the case of multiple predictors.

If the investor performed an OLS regression of monthly excess stock and bond returns on the predictive variables in the previous month, he would obtain the following estimated coec cients and their associated p-values (in parentheses):

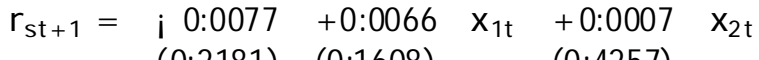

$$
\begin{aligned}
& \begin{array}{lll}
(0: 2181) \quad(0: 1608) \quad(0: 4257) & 0
\end{array} \\
& +0: 0054 \quad x_{3 t} \quad \text { i } 0: 0004 \quad x_{4 t} \quad+^{2}{ }_{s t+1} \\
& \text { (0:0071) } \quad(0: 2291) \\
& \begin{array}{l}
\text { i } 0: 0004 \quad x_{4 t} \quad t^{2} s t+1 \\
(0: 2291)
\end{array} \\
& r_{b t+1}=\begin{array}{ccccc}
0: 0002 & +0: 0038 & x_{1 t} & \text { i } 0: 0008 & x_{2 t} \\
(0: 4814) & (0: 1333) & & (0: 3288) &
\end{array} \\
& +0: 0024 \quad x_{3 t} \quad \text { i 0:0009 } \quad x_{4 t} \quad+^{2} b t+1 \\
& (0: 0140) \quad(0: 0010)
\end{aligned}
$$

where $r_{\text {st }}$ and $r_{\text {bt }}$ stand for continuously com pounded excess returns on the stock and the 10-year bond indices respectively, and $x_{i t} ; i=1 ; 2 ; 3$; and 4 denote the value in month $t$ of the default spread, DP, the term spread, and the stock index trend.

In regression (17) only the term spread is signi..cantly dixerent from zero, whereas in regression (18) the term spread and especially the trend have a signi..cant predictive power over next month's expected return. On the other hand, the $\mathrm{R}^{2}$ coet cient equals 0.0211 in the case of stocks and 0.0319 for bonds. These results show the magnitude of the investor's problem of deciding whether he should consider the empirical evidence on predictability or whether he should think that evidence is too weak to take the regression estimated coed cients as the true model parameter values. The B ayesian approach can thus be seen as an intermediate solution between both extreme attitudes.

Tables 1 and 2 summarize the main descriptive statistics of the data set, and ..gure 1 plots the predictors.

\section{Portfolio problem with a single risky asset}

Suppose that the investor's problem amounts to simply choosing the fraction of his portfolio to be invested in the riskless asset and in a mutual fund that replicates returns on a risky asset (a stock or a 10-year bond index), so that 
he maximizes his expected utility at a given time in the future. The investor's problem is next analyzed in the context of Barberis (2000), namely with a single predicting variable and both from an empirical and theoretical perspective. Results are then presented for the case of multiple predictors when a portfolio of long-term bonds is the only risky asset available both with and without parameter uncertainty.

\subsection{Single predictor}

Suppose that the investor believes that there exists a single variable with predictive power over future monthly excess returns. In the presence of a single risky asset, the return generating model can be written as:

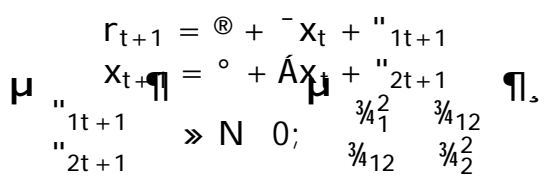

where $r_{t}{ }^{\prime} r_{s t}$, and $x_{t}{ }^{\prime} D P_{t}$ in the case of stocks and $r_{t}{ }^{\prime} r_{b t}, x_{t}{ }^{\prime}$ Trend for bonds. The ..xed values of the model parameters in both cases are shown on table 4.3 and are obtained from the O LS estimation of (19).

Figure 2 shows the investor's optimal allocation to stocks when paramet er uncertainty is not taken into account. A utility maximizing investor should allocate a larger fraction of his wealth to stocks the higher the value of DP and the longer the investment horizon. B oth exects can only be attributed to predictability. If stock returns where i.i.d., the distribution of fut ure returns would be independent of the current value of the predicting variable. Furthermore, in the i.i.d. case, both the mean and the variance of cumulative excess returns would grow linearly in the horizon so the ratio of both would be constant across all investment horizons.

The interesting question is why the optimal demand for stocks is increasing in the investment horizon.

B rennan, Schwartz and Lagnado (1997) and Barberis (2000) provide the same explanation: predict ability induces mean reversion in monthly excess stock returns which in turn makes the variance of cumulative excess returns grow less than linearly as the investment horizon increases. Intuitively, a sudden shock to the stock return at a given period is most likely to happen when the predictor experiences a shock of op posite sign because $3 / 42<0$. Since ${ }^{-}>0$; the shock in $D P_{t}$ translates to $r_{t+1}$ resulting in negative serial correlation in returns. As a consequence, the risk of investing in the stock grows less than linearly as the horizon increases which makes stocks more attractive as a long-term investment.

The above reasoning seems to suggest that negative serial correlation in returns justi..es by itself a positive horizon exect as that found by $B$ arberis and shown on ...gure 2. A ccordingly, it would be reasonable to expect the demand for long-term bonds to also increase in the investment horizon when variable trend is the only predictor, since in this case $3 / 42>0$ and ${ }^{-}<0$. However none 
of the previous conclusions is true. First of all, the fact that $3 / 42$ and ${ }^{-}$have dixerent signs is not a su $\phi$ cient condition for the variance of cumulative returns to be concave in the horizon, as shown below. Furthermore, the fact that the variance grows less than linearly with the investment horizon does not imply that the investor prefers to allocate more to stocks the longer the horizon. The reason is that the evolution of optimal demand with the horizon depends upon the joint variation of both the variance and the mean of cumulative returns.

The forthcoming paragraphs deal with the above questions by analyzing the dependence of the mean variance ratio of cumulative returns on the horizon in the context of model (19) and trying to answer the following questions:

1. What are the conditions under which the variance and the mean of cumulative returns are concave or convex in the invest ment horizon?

2. How can the answer to the previous question be exploited in order to analytically characterize the dependence of the mean variance ratio on the horizon?

$\mathrm{F}$ irst, the variance of the cumulative return between periods $\mathrm{t}$ and $\mathrm{t}+\mathrm{n}$ is analyzed. A pplying the general result (11) to model (19) it follows that:

$$
\begin{aligned}
& v_{n}{ }^{\prime} \quad \operatorname{var}_{t}\left(R_{t+n}\right)=v_{n_{i} 1}+3 / 2 / 4+\left({ }^{-}+{ }^{-} A ́+\$ \$ \$+{ }^{-} A^{n_{i} 2}\right)^{3 / 42}+
\end{aligned}
$$

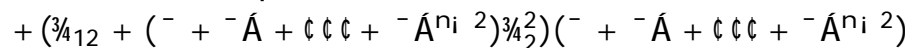

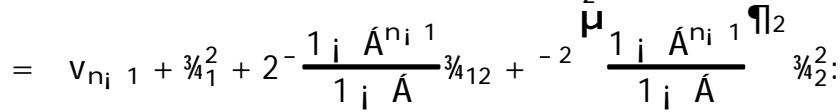

which holds for $n=1 ; 2 ; ф \pitchfork \emptyset 1$; with $v_{0}=0$ : If $r_{t+n}$ were unpredictable, i.e. - $=0$; then $v_{n}=n 3 / 4$. The variance in that case would be linear and ..rst-order homogeneous in $\mathrm{n}$.

In order to know if one-period changes in the variance of the cumulative return are increasing or decreasing in the horizon, it is necessary to calculate the ..rst derivative of $v_{n} i v_{n_{i}}$ with respect to $n$ :

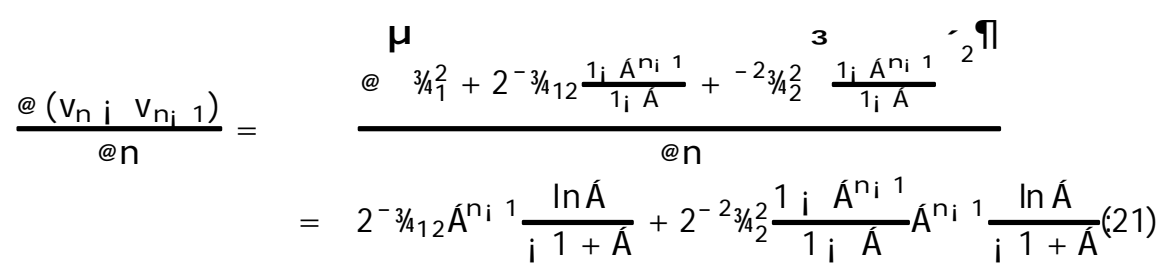

Under the assumption that the predictive variable is stationary, i.e, jÁj < 1 ; it follows that the variance grows more than linearly in $\mathrm{n}$ if the following condition holds:

$$
-3 / 42>i-23 / 2 \frac{1 i A^{n_{i} 1}}{1 i \dot{A}}:
$$


Given that the right hand side of (22) is always negative, when ${ }^{-}$and $3 / 42$ have the same sign the above condition is always met. However, when ${ }^{-}$and $3 / 42$ have opposite signs, it is not possible to assert whether their joint exect is en ough to make the variance grow less than linearly. In other words, negative serial correlation does not imply that $\mathrm{v}_{\mathrm{n}}$ is concave in $\mathrm{n}$ :

$\mathrm{O} n$ the other hand since $\mathrm{j} A \mathrm{j}<1$; as the horizon grows to in...nity one-period increments in the cumulative variance become constant:

$$
\lim _{n ! 1}\left(v_{n} i \quad v_{n_{i} 1}\right)=3 / 4 \text { / }+\frac{2^{-3 / 42}}{1_{i} A}+\frac{-2_{3 / 2}}{\left(1_{i} A\right)^{2}}:
$$

It follows that in the limit the variance of cumulative returns becomes linear in the investment horizon.

As for the mean of excess cumulative returns, its growth between $n_{i} 1$ and $n$ is simply the mean of the monthly return between periods $t+n ; 1$ and $t+n$ :

$$
\begin{aligned}
& m_{n}, \quad E_{t}\left(R_{t+n}\right)=E_{t}\left(R_{t+n_{i} 1}\right)+E_{t}\left(r_{t+n}\right) \\
& =m_{n_{i} 1}+{ }^{\circledR}++^{-\circ}+{ }^{-\circ} \dot{A}+{ }^{-\circ} A^{2}+\Phi \nsubseteq \Phi+{ }^{-\circ} A^{n_{i} 2}+{ }^{-} A^{n_{i}{ }^{1}} x_{t} \text { : }
\end{aligned}
$$

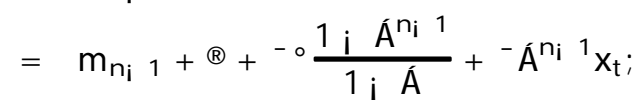

which holds for $n=1 ; 2 ; \nsubseteq \pitchfork \varnothing 1 ;$ with $m_{0}=0$ : A gain, unpredictability implies that $m_{n}=n m_{1}$. Dixerentiating $m_{n} i m_{n_{i}}$ with respect to $n$ gives:

$$
\begin{aligned}
& \frac{@\left(m_{n} i m_{n_{i} 1}\right)}{@}=\frac{@^{3}\left({ }^{-}+\circ \frac{1_{i} A^{n_{i} 1}}{1_{i} A}+{ }^{-} A^{n_{i} 1} x_{t}\right.}{@} \\
& =-\dot{A}^{n_{i} 1} \frac{\ln \hat{A}}{i 1+\dot{A}}\left({ }^{0} i \quad x_{t}(1 ; \quad A)\right) \text { : }
\end{aligned}
$$

So, when ${ }^{-}>0$; the mean of cumulative returns $m_{n}$ grows mor e than linearly with $\mathrm{n}$ if:

$$
x_{t}<\frac{\circ}{1 i A^{\prime}}
$$

i.e., if the predictor's initial value is below its long-run mean, and less than linearly otherwise.

Note that the exect of the predictor's initial value on $\frac{\left(m_{n} m_{n} m_{1}\right)}{a_{n}}$ has an opposite sign to that on $E_{t}\left(r_{t+n}\right)$. As a consequence, when $x_{t}$ axects $E_{t}\left(r_{t+n}\right)$ positively, its increments decrease as the horizon becomes longer if the predictor is initially above its long-run mean. Int uitively, when the predicting variable is stationary, the infuence of the predictor's initial value on each period's return decays with time. The larger the initial exect of the predicting variable, the larger the loss in the cumulative expected retur $\mathrm{n}$ as $\mathrm{n}$ increases. 
Taking limits in $m_{n} i m_{n_{i} 1}$; it follows that:

$$
\lim _{n ! 1}\left(m_{n} i m_{n i 1}\right)=®+{ }^{-} \frac{\circ}{1 i_{i}} ;
$$

so just as happens with the variance, as the horizon grows to in..nity the mean of cumulative returns grows linearly in $\mathrm{n}$.

Conditions (22) or (27), and (??) determine whether the mean and variance of the cumulative return are linear functions in the investment horizon or whether they exhibit concavity or convexity. Next question is what conclusions can be drawn from the previous analysis regarding the evolution of the mean variance ratio with the investment horizon.

$B$ etween two dixerent horizons $n_{1}$ and $n_{2}$; the mean variance ratio grows if the mean increases more than the variance in relative terms. For the case in which $\mathrm{m}_{\mathrm{n}_{1}}>0$ :

$$
\frac{m_{n_{2}}}{v_{n_{2}}}>\frac{m_{n_{1}}}{v_{n_{1}}}() \frac{m_{n_{2}}}{m_{n_{1}}}>\frac{v_{n_{2}}}{v_{n_{1}}}:
$$
then:

If $\mathrm{m}^{0} \mathrm{~s}$ homogeneity order in $\mathrm{n}$ is higher than one and $\mathrm{v}^{\mathrm{S}} \mathrm{s}$ is lower than one,

$$
\frac{m_{k n}}{m_{n}}>k>\frac{v_{k n}}{v_{n}} ;
$$

in that case the mean variance ratio is always increasing in $\mathrm{n}$.

$\mathrm{O} n$ the other hand, if $\mathrm{m}$ is a convex function in $\mathrm{n}$ and $\mathrm{v}$ is concave, then:

$$
\frac{m_{k n} i m_{0}}{m_{n} i m_{0}}>k>\frac{v_{k n} i v_{0}}{v_{n} i v_{0}}:
$$

Since $m_{0}=v_{0}=0$; it can be concluded that the mean variance ratio is increasing in $\mathrm{n}$ when the mean grows more than linearly in $\mathrm{n}$ and the variance grows less than linearly. The converse reasoning could be used to show that when $\mathrm{m}$ is concave and $\mathrm{v}$ is convex in $\mathrm{n}$, the ratio is decreasing in the horizon. of course, the ..nal exect when both the mean and variance are either concave or convex in $\mathrm{n}$ is ambiguous.

Finally, note that in the limit the mean variance ratio is constant and the horizon exect on the optimal demand vanishes. Of course, this result is only true when jÁj $<1$ :

Consider next the static portfolio choice problem when the long-term bond portfolio is the only risky investable asset. Suppose that the investor believes that the return on that portfolio evolves according to model (19) and thinks that the true parameter values ar e those from table 3. O ptimal asset allocation must be higher for a lower initial value of the predictor since ${ }^{-}<0$. According 
to condition (22) it is possible to verify that $v$ grows less than linearly with the investment horizon. A dditionally, condition (??) does not hold when the predictor's initial value equals i 1 since $^{\circ}>0$; so in that case the mean grows less than linearly. When the trend's initial value equals 2 , the mean is almost linear in $\mathrm{n}$; and ..nally for an initial value of 5 condition (??) is met, so the mean of cumulative returns grows more than linearly.

Figure 3 shows graphically the results from solving the investor' problem of allocating his investment betwen the risk free asset and the bond portfolio . When trend initially equals i 1 ; the investor's position in the 10 -year bond portfolio is larger than when the trend's initial value equals 2 and double his optimal position when it equals 5 . This is simply a consequence of ${ }^{-}$being negative. More interestingly, the predictor's initial value not only axects the level of the investor's optimal demand but it also determines the sign of the horizon exect. In particular, optimal demand decreases when trend is initially $i$; and increases when trend equals 5 . This result is consistent with the theoretical analysis. Since ${ }^{-}<0$; increases in $\mathrm{E}_{\mathrm{t}}\left(\mathrm{r}_{\mathrm{t}+\mathrm{n}}\right)$ are growing in the investment hor $\mathrm{i}-$ zon when the predictor's initial value is above its long-run mean, and decreasing other wise. This exect dominates that on the cumulative variance, so the horizon exect can be either increasing or decreasing depending on the predictor's initial value. This is in striking contrast to what happens as the investment horizon increases when investment in stocks is considered. In that case, given the parameter estimates the horizon exect on the variance is dominant and makes the optimal demand for stocks to be increasing in the investment horizon regardless of the predictor's initial value.

\subsection{General Model}

Next, a general model that includes both stocks and long-term bonds as well as the four predicting variables is estimated and the investor's portfolio problem is solved when the long-term bond portfolio is the only risky investable asset. $W$ hen the investor does not recognize estimation risk, it will be assumed that he takes as the true parameter values the means of $C$ and $\S$ from the posterior distribution given by $\mathrm{p}(\mathrm{C} ; \S \mathrm{j} \mathrm{z})$; as shown on tables 4.4 and 4.5 .

Figures $4,5,6$, and 7 display the solution the investor's problem when returns are assumed to be generated by a general model with four predicting variables with parameter values as sh own on tables 4 and 5 . Each graph plots the solution to the maximization problem for dixerent investment horizons and three dixerent cases that correspond to three dixerent initial values of one particular predictor. The values considered are the 25 th sample percentile, the sample, and the 75th sample percentile of the predicting variable chosen in each case. The initial values for the rest of variables are taken to be their sample means. This way, it is possible to study the isolated exect of the initial value of each predictor on the evolution of the demand with the horizon. In each case a similar pattern is found: when the coec cient in the regression equation for a given variable is positive, optimal demand is larger but decreasing in the investment horizon for initial values above the predictor's sample mean, and smaller but increasing 
for lower initial values. On the other hand, when the regression coed cient is negative, the situation is inverted. Consistently with the theoretical analysis, the horizon exect disappears at long horizons. As opposed to the case when only stocks are available, horizon exects arise only when the initial values of the predicting variables depart from their historical average.

W hen the in $¥$ uence of the trend alone is considered (..gure 7), an investor with a relative risk aversion coec cient of 5 doubles his allocation into bonds when his investment horizon increases from 2.5 years to 10 years if the trend's initial value is high. Interestingly, including multiple predictors in the model does not alter the conclusions drawn from the single predictor case as long as the rest of variables are initially about their historical means. It thus would seem that, at least for the case of Government B onds, model risk is negligible as long as the investor considers the only predictor whose initial value departs from its sample average. On the other hand, ..gure 5 shows that optimal demand lines converge less rapidly for dixerent initial values of DP. This is explained by the high persistence in the dividend yield series, which makes the in $\ddagger$ uence of the predictor's initial value last for a long number of periods. As a consequence, important dixerences in the investor's position due to the initial value persist even when the investment horizon is 10 years apart.

W hen the investor acknowledges that the true values of the model parameters may depart from those on tables 3 and 4, he must incorporate estimation risk into his portfolio decision problem. F igure 8 shows the invest or's optimal position in long-term bonds when parameter uncertainty is taken into account. J ust as happens with stocks (B arberis (2000)), introducing estimation risk increases dispersion in the possible realizations of the future cumulative return which makes the risky asset appear riskier to the long-term investor's eyes. However, the investor's position as well as its evolution with the horizon is affected as dramatically as in the case studied by Barberis. In fact, estimation risk is higher for stocks than for $G$ overnment $B$ onds as can be seen from the ${ }^{2}$ coet cients obtained in the predictive regressions. Besides, it is consistent with Elton's (1999) argument that estimation of future expected returns from past realized returns are better for Government bonds than for other assets since G overnment Bonds contain little speci..c information that can axect their price. Elton provides ..ve reasons to support his argument: the factors that axect Government B ond prices can be found in the form of aggregated economic information; there exists wide consensus on what economic variables should axect bond prices; potentially important variables axect all agent; the moment when information about these variables is known and ..xed; and ..nally, the impact of the unexpected component of these announcements is rapidly incorporated into prices.

\section{Dynamic allocation}

B arberis (2000) observes that as the predicting variable changes over time, it also changes the investment opportunity set faced by the investor, namely it 
changes the investor's expected future return. Since shocks to the dividend yield are highly negatively correlated with shocks to stock returns, then higher realized returns will occur when the dividend yield -and hence future expected return- is relatively low. Therefore, allocating an extra amount to stock returns can be a good way to hedge periods of poor investment opportunities. Solving the B ellman equation numerically by backward induction, Barberis is able to characterize the solution to the asset allocation problem of an investor who rebalances his portfolio every year when the stock index is the only investable risky asset. Barberis ..nds that Merton's intertemporal hedging demand for stocks is positive and increasing in the investment horizon. Does this result extend to the case of long-term $\mathrm{G}$ overnment bonds?

Note from table 3 , that shocks to bond returns most likely occur when the predicting variable-trend-is axected by shocks of the same sign. Since a higher current level of the predictor implies a lower future expected return, long-term bonds in principle appear to be a good way to hedge adverse changes in the investment opportunity set. Figure 9 shows optimal portfolio weights of an investor who believes that bond returns are predicted by current trend levels and who rebalances his portfolio every month. It seems clear that contrary to the optimal hedging demand for stocks, in the absence of inłation risk, the investor's hedging demand for long-term bonds is zero for all investment horizons and initial values of the predictor ${ }^{5}$. Although not reported, results for the rest of predictors do not alter this conclusion.

\section{Portfolio choice with two risky assets}

This section considers the problem of an investor who can invest in the riskless asset as well as in the stock index and the 10-year bond portfolio. Figure 10 summarizes the results graphically for two cases: when the trend's initial value is at its 25th sample percentile and when it is at its 75th sample percentile. Graphs show that the horizon exect on the investor's position in long-term bonds extends to the two risky asset case, namely, the investor increases his position in bonds with the horizon if the trend's initial value is unusually high and viceversa. However, comparing ..gure 10 with ..gure 7, it can be veri..ed that the horizon exect on the bond demand in the presence of stocks does not exhibit the same degree of symmetry. Since the appeal of stocks increases so rapidly with the investment horizon, the investor's position in bonds decreases more when the trend's initial value is low and increases less when the trend's initial value is high than when only bonds are available. A similar observation can be made when estimation risk in $¥$ uences the investor's decision (..gure 11). In this case, however, estimation risk severely penalizes the investor's position

\footnotetext{
${ }^{5} \mathrm{~T}$ he approach employed for solving Bellman's equation recursively is basically that proposed by Barberis except for the fact that splines have been used to interpolate between consecuti ve elements of the discretized state space. The advantage is that fewer design points are needed and hence precious computing time can be used to increase the rebalancing frequency.
} 
in stocks, so the negative in uence on the horizon exect of his position in bonds is more likely a result of parameter uncertainty alone.

Changes in the trend's initial value axect expected returns on stocks and bonds in the same direction. In the following paragraphs, changes in the dividend yield's initial value are considered since this predict or's exect is opposite for each asset's future returns.

The upper graph of ..gure 12 corresponds to the case when DP is initially at its 25th sample percentile, the central graph corresponds to a situation in which all predictors initially take on their mean values, and ..nally the lower graph shows the evolution of the investor's portfolio with the horizon when D P is initially at its 75th sample percentile. T wo main conclusions can be drawn from ..gure 12 .

F irst, as the investment horizon increases, the investor increases his position in stocks and decreases the portfolio weight in the riskless asset. Changes in the predictor's initial value do not substantially alter the horizon exect on the investment in stocks or the levels of investment for every horizon. However, a higher initial value of DP decreases the investor's position in long-term bonds and decreases the negative horizon exect.

Second, it is interesting to note that predictability makes asset substitution - as a response to changes in the predict or's initial value- depend on the investment horizon. In particular, when the investment horizon is short, a higher initial value of the DP induces the investor to decrease his position in bonds and increase his position in the riskless asset. $\mathrm{O} n$ the other hand, when the investment horizon is long, when DP increases, the investor allocates less to bonds and more to stocks.

Figure 13 shows that under parameter uncertainty the investor's position in stocks is practically constant in the investment horizon for any initial value of the predicting variable. As for bonds, under parameter uncertainty there is a negative horizon exect for any of the predict or's in itial values. A s a consequence, as the horizon increases, the investor always increases his position in the riskless asset at the expense of long-term bonds. Comparing with the previous ..gure, for long horizons introducing estimation risk has a dramatic impact on the position in stocks: when predictors are initially at their mean levels, the investor's optimal position in stocks falls by half. A gain, the impact of estimation risk on the weight in bonds is less evident.

A nother interesting question is how optimal asset allocation varies with the investor's degree of risk aver sion for a ..xed investment horizon. F igure 14 shows results for this analysis. J ust as in Campbell and Viceira (1988) the dem and for long-term bonds arises when the degree of risk aversion surpasses a given level and from that level on it slowly decreases as the risk aversion coed cient becomes larger. Besides, a more risk averse invest or allocates less resources to stocks and more to the riskless asset. It must be not ed that the investor's optimal position in bonds is sensibly higher than the "myopic" demand found by Campbell and Viceira (1998). Given the small horizon exect detected for long-term bonds in the presence of stocks, this dixerence cannot be attributed to the horizon exect, but rather to the absence of inłation risk in the present analysis. 
Consistently with mean variance analysis, the fraction of 10 -year bonds in the risky asset portfolio is stable for dixerent degrees of risk aversion (31.5 per cent approximately), except for, of course, when the short sale restriction is exective. When the investor takes estimation risk into account (lower graph) although returns are no longer normally distributed, the fraction of the risky portfolio invested in long-term bonds is constant for all risk aversion coed cients considered and equals $1=3$. Since estimation risk increases investment in the riskless asset, in terms of proportion relative to the total portfolio, parameter uncertainty has a larger impact on the investor's position in stocks than on the investor's allocation to bonds. For instance, when the risk aversion coed cient equals 10 , stocks capture 47.5 per cent of the total portfolio without estimation risk and 32.5 percent with estimation risk, whereas investment in bonds reduces from 22.5 per cent to 17.5 per cent of the total portfolio.

\section{Conclusions}

This study addresses for the ..rst time the question of horizon exect on the demand for $\mathrm{G}$ overnment debt when ret urns are predictable. It is well known that just as hap pens with stocks, bond returns also exhibit negative serial correlation. If negative serial correlation were a su $\$$ cient condition for the positive horizon exect found in stocks, then it would be reasonable to expect the same exect on the demand for long-term bonds. Numerical results however do not support this hypothesis. Horizon exects can either be positive or negative depending on whether the predictor's initial value is lower (higher) or higher (lower) than its historical mean when the regression coet cient is positive (negative). In the very long term horizon exects disappear, just as happens when the predictors' initial values are around their sample means. These results are supported by a theoretical analysis of the mean variance ration of cumulative returns for the case of a single risky asset and a single predictor. Intuitively, the in $\neq$ uence ( positive or negative) of the predictor's initial value tends to decay with time when the explaining variable is stationary. Stationarity thus induces optimal demands for dixerent initial values of the predictor to converge in the limit whenever the mean horizon exect dominates that on the variance. This may thus imply both positive and negative horizon exects.

Introducing parameter uncertainty in the invest or's problem decreases both the level of investment for every horizon as well as its growth as the horizon increases. Estimation risk seems to have a larger impact on the demand for stocks than on that for Government Bonds.

The dynamic allocation problem shows that optimal hedging demands for long-term bonds are negligible at all investment horizons.

F inally, optimal asset allocation when both risky assets are available seems to be highly consistent with the single risky asset case.

The results of the analysis have consequences both in terms of further approximating to the exect of predictability on optimal portfolio choice, as well as in more practical terms given the weight of investment by mutual funds in 
..xed income assets.

A n interesting extension, already pointed out by Kandel and Stambaugh (1996) is the problem of incorporating conditional heteroscedasticity in the model, which is likely to axect the way predictability axects optimal portfolio choice.

On the other hand, and in the context of parameter uncertainty, the use of informative prior probability density functions would enable us to see how optimal asset allocation varies for dixerent degrees of con..dence in dixerent models. R elated to this point, A vramov (1999) has studied model risk in portfolio choice with stock portfolios.

Finally, it should be remembered that the implications of optimal portfolio choice under predictability in a general equilibrium context are yet to be explored. 


\section{R eferences}

Aït-Sahalia, Yacine and Michael Brandt, 2001, Variable selection for portfolio choice, J ournal of $F$ inance, forthcoming.

A vramov, Doron, 2000, Stock return predictability and model uncertainty, Working Paper, University of M aryland.

Balduzzi, Pierluigi, and Anthony Lynch, 1999, Transaction costs and predictability: some utility cost calculations, J ournal of $\mathrm{F}$ inancial E conomics $52,47-48$.

Barberis, Nicholas, 2000, Investing for the long-run when returns are predictable, J ournal of Finance 55, 225-264.

Brandt, Michael W., 1999, Estimating portfolio and consumption choice: A conditional Euler equations approach, J ournal of Finance 54, 1609-1646.

Brennan, Michael J ., Eduardo S. Schwartz, and Ronald Lagnado, 1997, Strategic asset allocation, J ournal of E conomic D ynamics and Control 21, 13771403.

Campbell, J ohn $Y$., 1987, Stock returns and the term structure, J ournal of Financial E conomics, 43, 373-399.

Campbell, J ohn Y., 1991, A variance decomposition for stock returns, The Economic J ournal 101, 157-179.

Campbell, J ohn Y., and R obert J . Shiller, 1988a, The dividend price ratio and expectations of future dividends and discount factors, Review of Financial Studies 1, 195-228.

Campbell, J ohn Y., and R obert J. Shiller, 1988b, Stock prices, earnings, and expected dividends, J ournal of Finance 43, 661-676.

Campbell, J ohn Y. and A lbert S. Kyle, 1993, Smart money, noise trading, and stock price behavior, Review of Economic Studies, 60, 1-34.

Campbell, J ohn Y . and Luis Viceira, 1998, W ho should buy long-term bonds?, Working Paper, Harvard University.

Campbell, J ohn Y . and Luis Viceira, 1999, Consumption and portfolio decisions when expected returns are time varying, Quarterly J ournal of Economics 114, 433-495.

Elton, Edwin J ., 1999, Expected return, realized return and asset pricing tests, J ournal of Finance 54, 1199-1220.

Fama, Eugene F., 1984, The information in the term structure, J ournal of Financial E conomics $13,509-528$. 
Fama, Eugene F., 1990, Term-structure forecasts of interest rates, inłation, and real returns, J ournal of M onetary E conomics 25, 59-76.

Fama, Eugene F., and K enneth R. French, 1988, Dividend yields and expected stocks returns, J ournal of Financial E conomics 22, 3-25.

Fama, Eugene F., and K enneth R. French, 1989, Business conditions and expected returns on stocks and bonds, J ournal of Financial Economics 25, 23-49.

Hansen, L ars P., and Ravi J agannathan, R estrictions on intertemporal marginal rates of substitution implied by asset returns, J ournal of Political Economy $99,225-262$.

Hodrick, Robert J., 1992, Dividend yields and expected stock returns: A Iternative procedures for inference and measurement, Review of Financial Studies 5, 537-386.

Ingersoll, J onathan E. J r., 1987, Theory of F inancial Decision Making ( Rowman and Little..eld: Savage, M aryland, EE.UU.).

Kandel, Shmuel, and R obert Stambaugh, 1996, On the predictability of stock returns: An asset allocation perspective, J ournal of Finance 51, 385-424.

Keim, Donald B ., and Robert F. Stambaugh, 1986, Predicting returns in the stock and bond markets, J ournal of Financial Economics 17, 357-390.

Klein, Roger W .,and Vijay S. Bawa, 1976, The exect of estimation risk on optimal portfolio choice, J ournal of Financial E conomics 3, 215-231.

Merton, Robert, 1969, Lifetime portfolio selection under uncertainty: The continuous time case, Review of E conomics and Statistics, 51, 247-257.

M erton, Robert, 1971, O ptimum consumption and portfolio rules in a continuous time model, J ournal of Economic Theory, 3, 373-413.

Merton, Robert, 1973, An intertemporal capital asset pricing model, Econometrica, 1973, 41, 867-887.

Pástor, Lubos, 1999, Portfolio selection and asset pricing models, J ournal of Finance, forthcoming

Restoy, Fernando, 1992, O ptimal portfolio policies under time-dependent returns, Bank of Spain, Working Paper 9207.

Samuelson, Paul A., 1969, L ifetime portfolio selection by dynamic stochastic programming, Revi ew of Economics and Statistics, 51, 239-246.

Zellner, A rnold, 1971, A Introduction to Bayesian Inference in E conometrics (J ohn Wiley and Sons, Nueva York, EE.UU.). 


\section{Tables}

Table 1. R eturns and predictors.

This table shows descriptive statistics of the return on the New York Stock Exchange index, the return on the 10-year US G overnment Bonds, the return on the one-month Treasury Bills, the default spread, the dividend yield on the stock index, the term spread and the stock index trend. Returns and observation frequency are monthly. Data cover the period from J anuary 1959 to December 1998. The sample size is 468 since 12 observations are lost.

\begin{tabular}{cccccccc} 
& Mean & Median & St. Dev. & A ssyimetry & K urtosis & M in & M ax \\
\hline Stocks & 0.009 & 0.012 & 0.043 & -0.709 & 3.256 & -0.246 & 0.152 \\
10-yr. Bonds & 0.006 & 0.003 & 0.022 & 0.382 & 1.386 & -0.069 & 0.095 \\
1-month Bill & 0.005 & 0.004 & 0.002 & 1.295 & 2.324 & 0.000 & 0.015 \\
Def. Spread & 0.997 & 0.850 & 0.450 & 1.246 & 1.404 & 0.32 & 2.690 \\
D P & 3.480 & 3.361 & 0.881 & 0.368 & -0.124 & 1.544 & 6.123 \\
Term Spread & 0.696 & 0.738 & 0.970 & -0.117 & 0.198 & -2.686 & 3.135 \\
Trend & 1.712 & 2.295 & 3.961 & -0.810 & 1.106 & -16.434 & 11.012 \\
\hline
\end{tabular}


Table 2. Correlations.

This table shows correlation coec cients in the sample between the variables ( $p$ anel $A$ ), as well as the serial autocorrelation coet cients for $1,3,6$, and 12 lags (pane B).

Panel A

\begin{tabular}{cccccc}
\hline & Bonds & Def. Spread & DP & Term Spread & Trend. \\
\hline Stocks & 0.2803 & 0.0979 & -0.1313 & 0.1515 & 0.4621 \\
B onds & 1 & 0.1129 & -0.0032 & 0.1336 & 0.0211 \\
Def. Spread & & 1 & 0.6635 & 0.0932 & 0.0617 \\
DP & & & 1 & -0.1800 & -0.3314 \\
Term Spread & & & & 1 & 0.2277 \\
Trend & & & & & 1 \\
\hline
\end{tabular}

Panel B

\begin{tabular}{ccccc}
\hline & $1 / 3$ & $1 / 3$ & $1 / 3$ & $1 / 32$ \\
\hline Stocks & 0.0601 & -0.0027 & -0.0662 & 0.0217 \\
10-year B onds & 0.0755 & -0.0685 & 0.0670 & 0.0096 \\
D ef. Spread & 0.9720 & 0.9055 & 0.8287 & 0.6813 \\
DP & 0.9812 & 0.9439 & 0.8812 & 0.7720 \\
Term Spread & 0.9609 & 0.8441 & 0.7189 & 0.5348 \\
Trend & 0.8783 & 0.6180 & 0.2483 & -0.1530 \\
\hline
\end{tabular}


Table 3. Single predictor VAR parameters.

$P$ arameter estimates on this table corresp ond to model:

$$
\begin{aligned}
& r_{t+1}={ }^{\circledR}+{ }^{-} x_{t}+" 1 t+1
\end{aligned}
$$

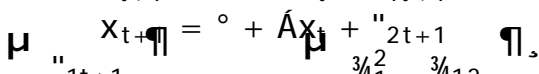

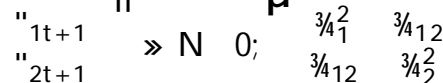

where $r_{t}$ is the continuously compunded monthly excess return on the risky asset (stocks or 10-year bonds) and $x_{t}$ is the predictive variable (DP or Trend, respectively).

R egression coec cients

\begin{tabular}{ccc}
\hline & Constant & DP \\
\cline { 2 - 3 } Stocks & -0.0044 & 0.0025 \\
DP & 0.0477 & 0.9862 \\
\hline
\end{tabular}

\begin{tabular}{ccc}
\hline & Constant & Trend \\
\cline { 2 - 3 } 10-year B onds & 0.0025 & -0.0007 \\
Trend & 0.2121 & 0.8787 \\
\hline
\end{tabular}

Covariance of residuals.

\begin{tabular}{ccc}
\hline \multirow{3}{*}{ Stocks } & Stocks. & DP \\
\cline { 2 - 3 } DP & 0.0019 & $-0.9296^{\infty}$ \\
\hline
\end{tabular}

\begin{tabular}{lcc}
\hline & & \\
\cline { 2 - 3 } 10-year B onds & 0.0005 & $0.2690^{\bar{\alpha}}$ \\
Trend & & 3.5932 \\
\hline
\end{tabular}

(Values marked with * are correlation coex...cients). 
Table 4.4. Posterior mean of $C$.

\begin{tabular}{cccccc}
\hline & Constant & D ef. spread & DP & Term Spread & Trend \\
\cline { 2 - 6 } Stocks & -0.0076 & 0.0066 & 0.0007 & 0.0053 & -0.0004 \\
10-year B onds & 0.0003 & 0.0038 & -0.0008 & 0.0024 & -0.0009 \\
D ef. spread & -0.0039 & 0.9499 & 0.0208 & -0.0142 & -0.0047 \\
DP & 0.0475 & -0.0462 & 1.0014 & -0.0195 & 0.0022 \\
Term spread & 0.0452 & 0.1522 & -0.0416 & 0.9581 & -0.0126 \\
Trend & -0.5764 & 0.3902 & 0.0791 & 0.1989 & 0.8705 \\
\hline
\end{tabular}

Table 4.5. Posterior mean of matrix $\S$.

Values above the main diagonal are correlation coet cients.

\begin{tabular}{ccccccc}
\hline & Stocks & B onds & Def. spread & DP & Term spread & Trend. \\
\cline { 2 - 6 } Stocks & 0.0019 & 0.2695 & 0.0783 & -0.9379 & 0.1399 & 0.9903 \\
B onds & & 0.0005 & 0.2485 & -0.2827 & 0.1620 & 0.2624 \\
Def. spread & & & 0.0102 & -0.0990 & 0.1634 & 0.0723 \\
DP & & & & 0.0289 & -0.1935 & -0.9325 \\
Term spread & & & & 0.0704 & 0.1318 \\
Trend & & & & & 3.5845 \\
\hline
\end{tabular}


Figures

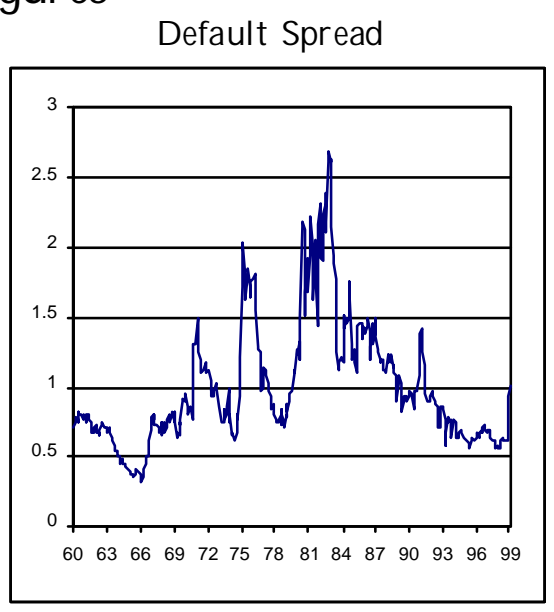

Dividend $Y$ ield

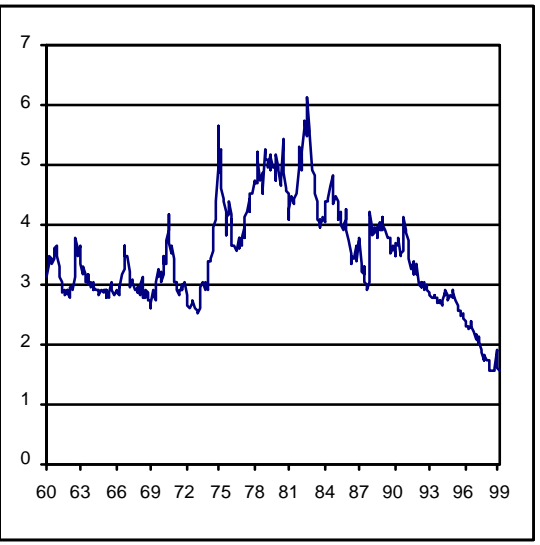

Term Spread

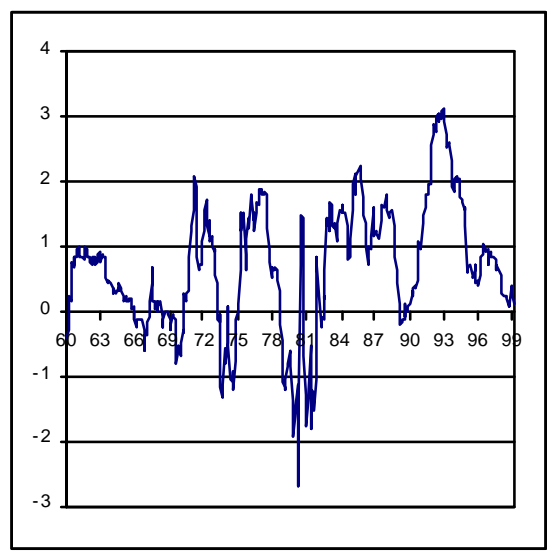

Trend

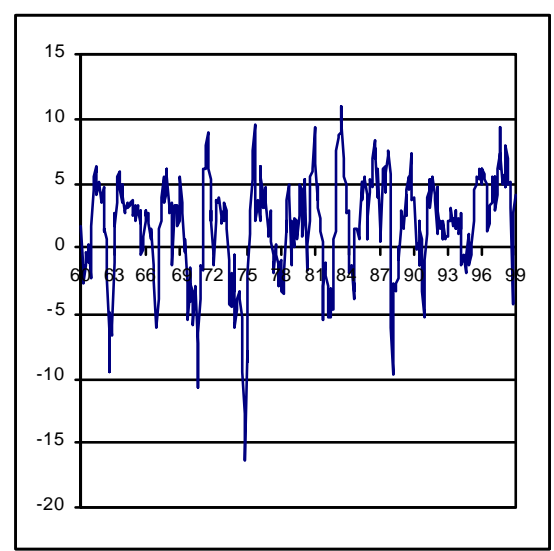

Figure 1. Predict ors. This ..gure shows the serial plot of the four variables chosen as predictors of the returns on the stock index and the 10-year bond index. The frequency of observation is monthly and data cover the period from J anuary 1959 to December 1998. T he sample size is 468 since 12 obser vations are lost. 


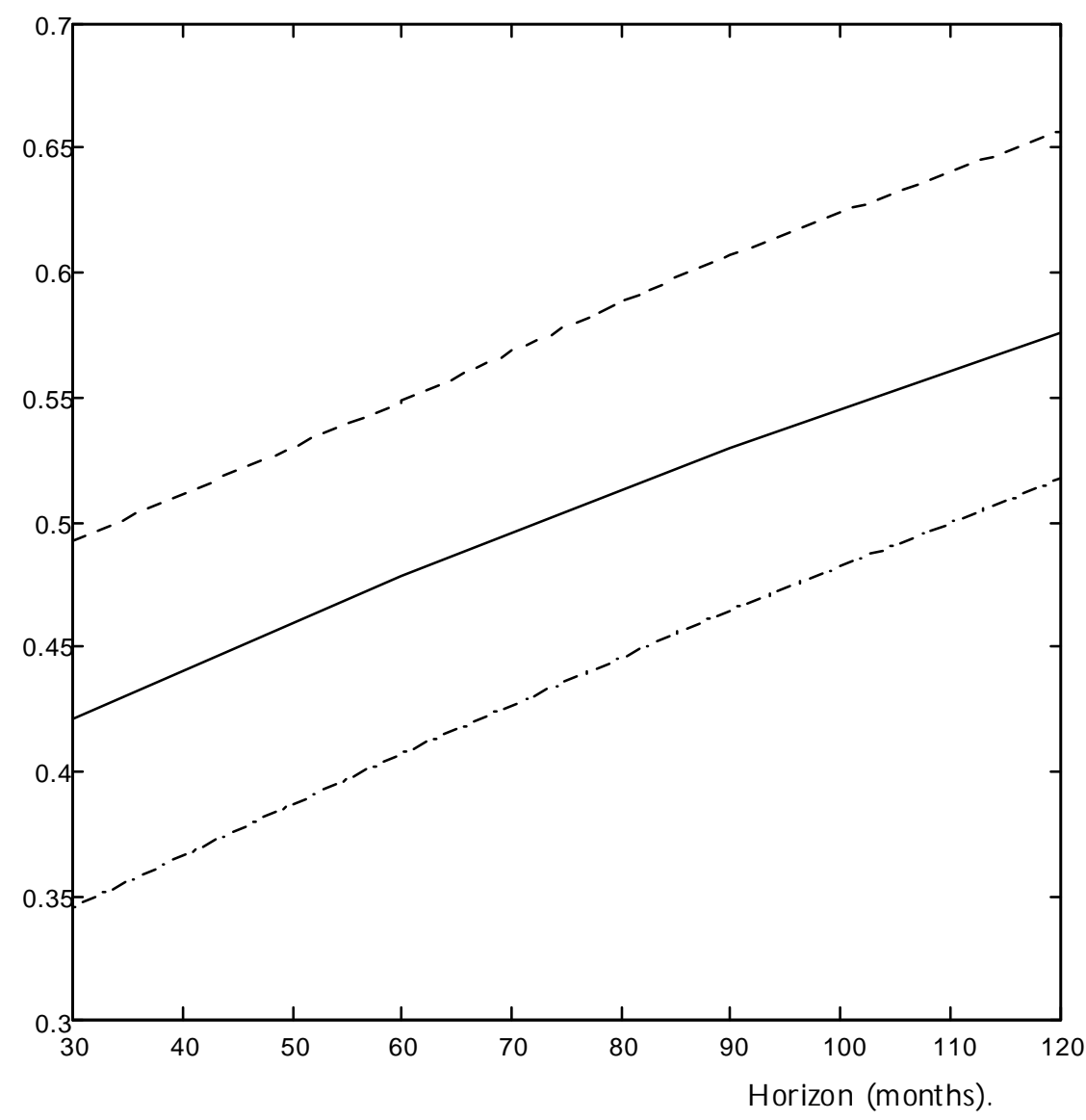

Figure 2. Allocation to stocks in the absence of Government Bonds as a function of the investment horizon when dividend yield is the only predictive variable. The graph plots the solution to the investor's static portfolio choice problem when the investment opportunity set contains the riskless asset and a stock index whose excess return is assumed to be generated by a VAR model that includes the dividend yield as the single predictor. The dash-dot line corresponds to an initial value of DP equal to 3.5 , the solid line to 4 , and the dash line 4.5 . 


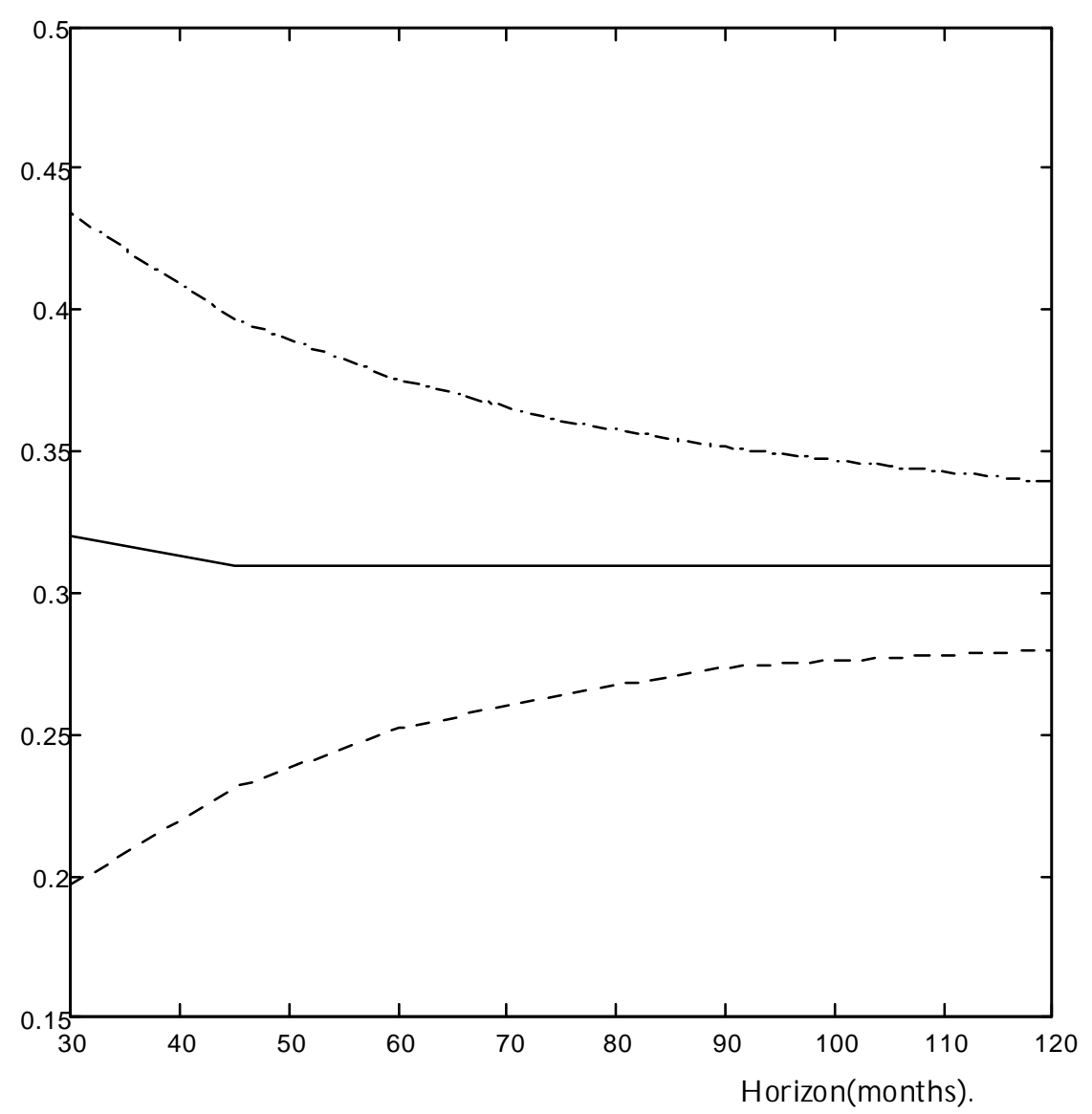

Figure 3. Allocation to long-term bonds in the absence of stocks as a function of the investment horizon when trend is the only predictor. The graph plots the solution to the investor's static portfolio choice when the investment opportunity set only contains the riskless asset and a 10-year bond portfolio whose excess return is assumed to be generated by a VAR model that includes trend as the single predictor. The dash-dot line corresponds to an initial value of trend equal to -1, the solid line corresponds to 2, and the dash line corresponds to 5 . The risk aversion coeф cient is 10 . 


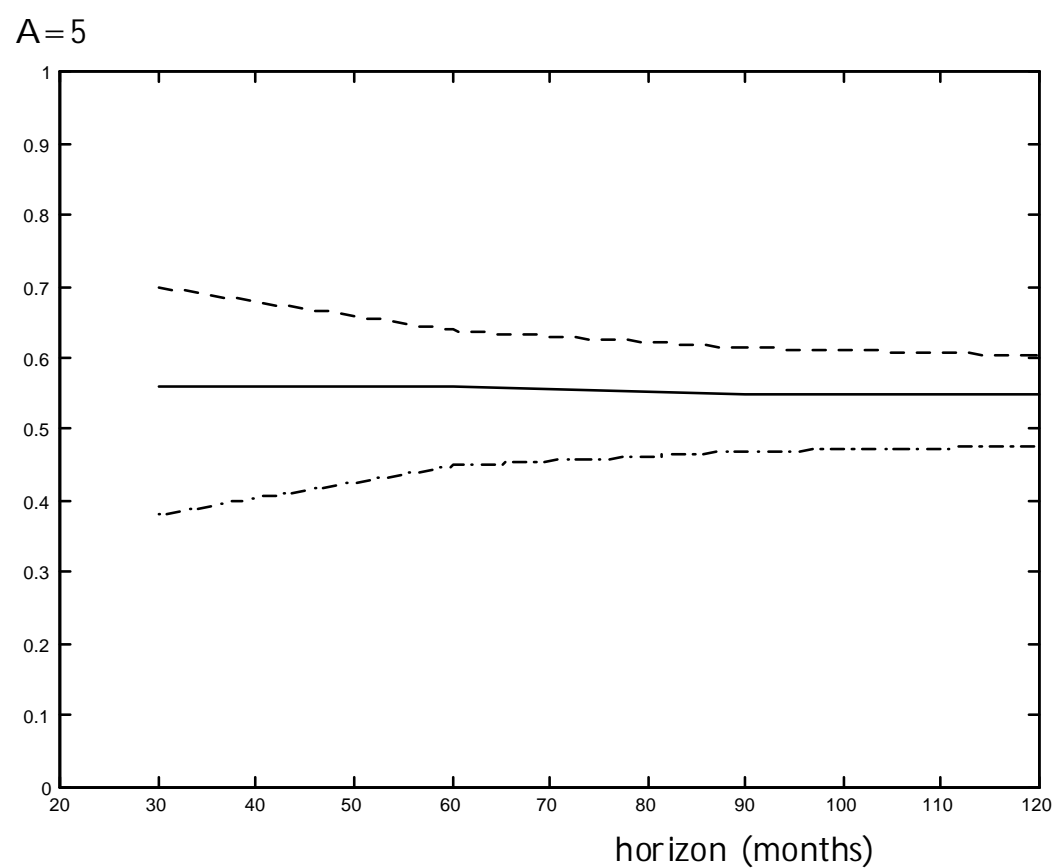

$A=10$

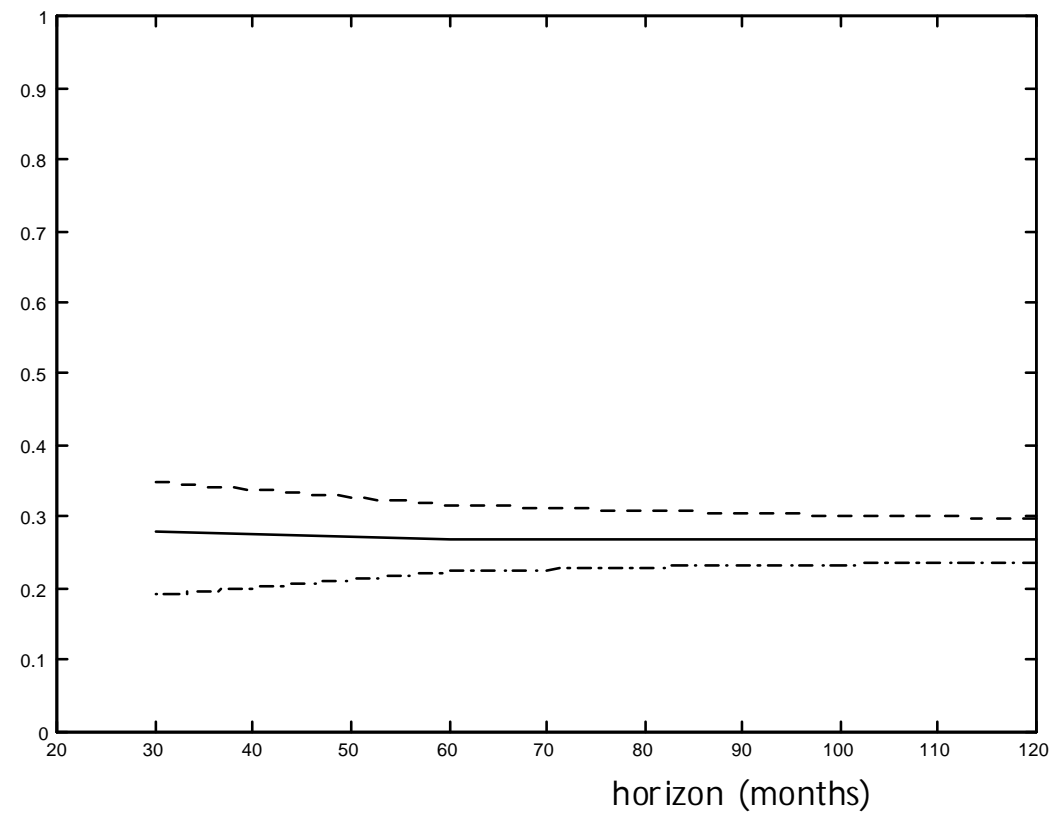

Figure 4. Allocation to bonds as a function of the investment horizon and the default spread. The graph plots for dixerent horizons the allocation to 10 -year bonds in the absence of stocks when returns are assumed to be generated by a VAR model with four predictors. The initial values of the default spread are 0.69 (dash-dot line), 0.99 (solid line), and 1.21 (dash line). In every graph, the initial valueszor the rest of variables are their sample means. 


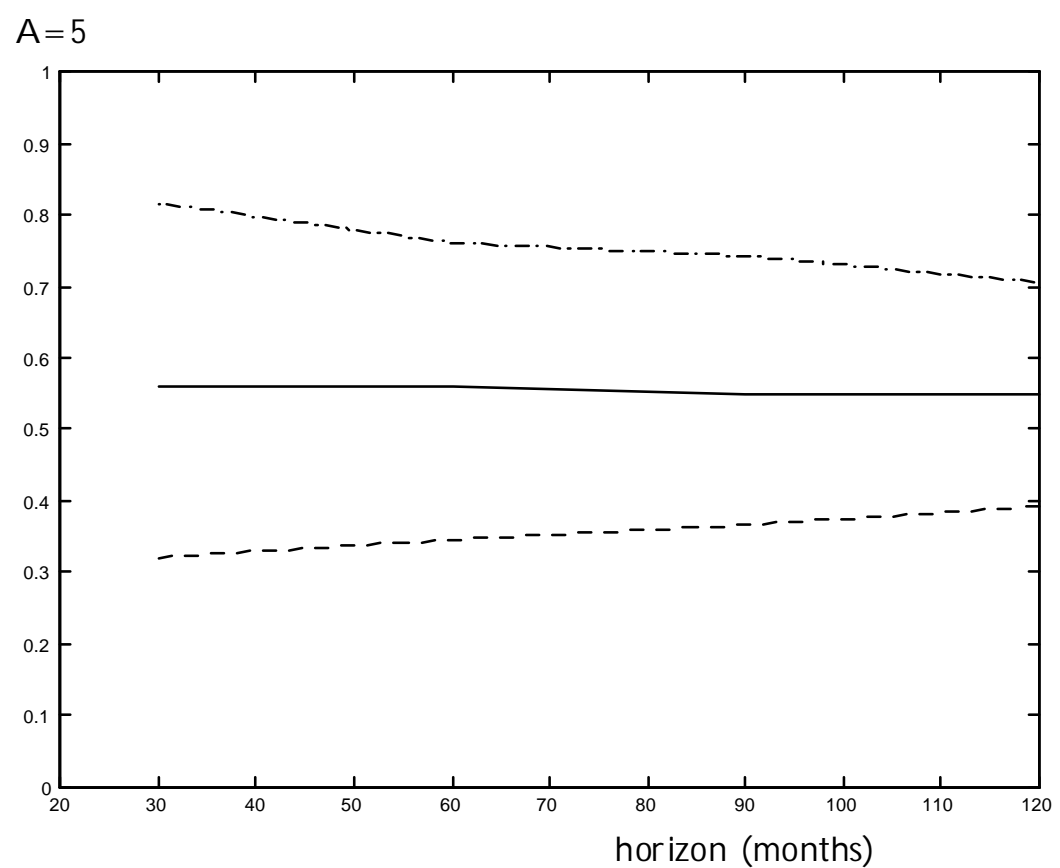

$A=10$

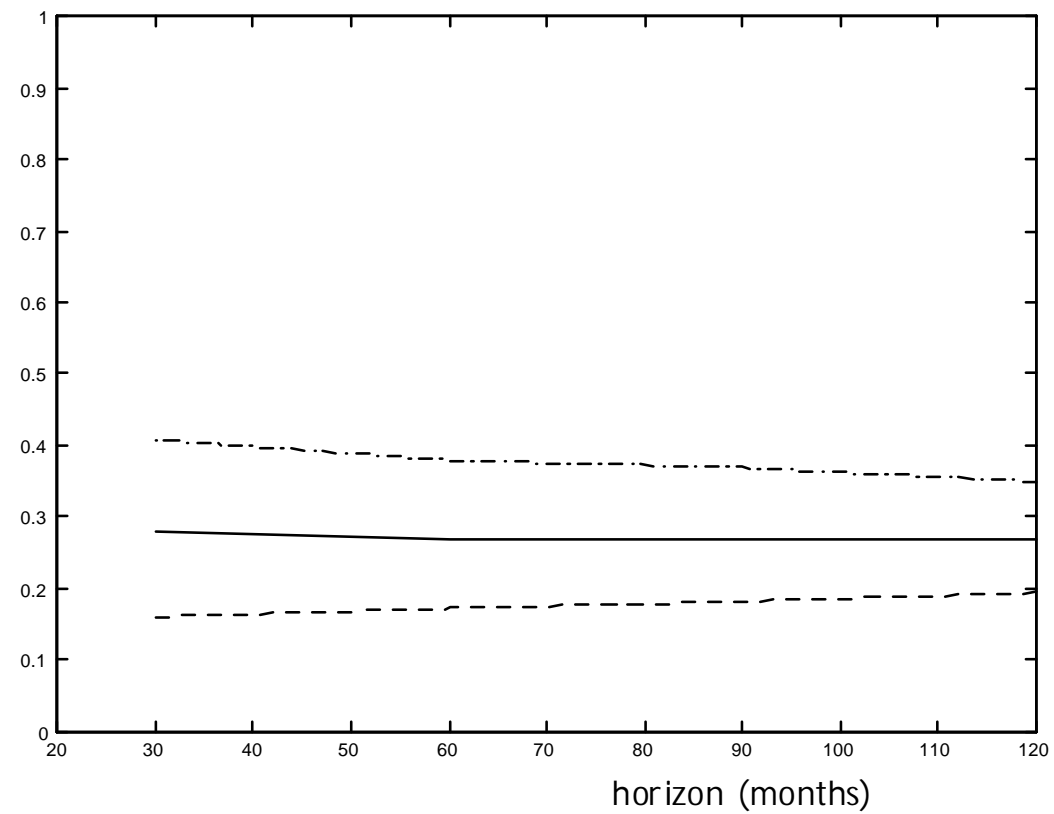

Figure 5. Allocation to bonds as a function of the investment horizon and the dividend yield. The graph plots for dixerent horizons the allocation to 10-year bonds in the absence of stocks when returns are assumed to be generated by a VAR model with four predictors. The initial values of the dividend yield are 2.88 (dash-dot line), 3.48 (solid line), and 4.07 (dash line). In every graph, the initial values 2 for the rest of variables are their sample means. 


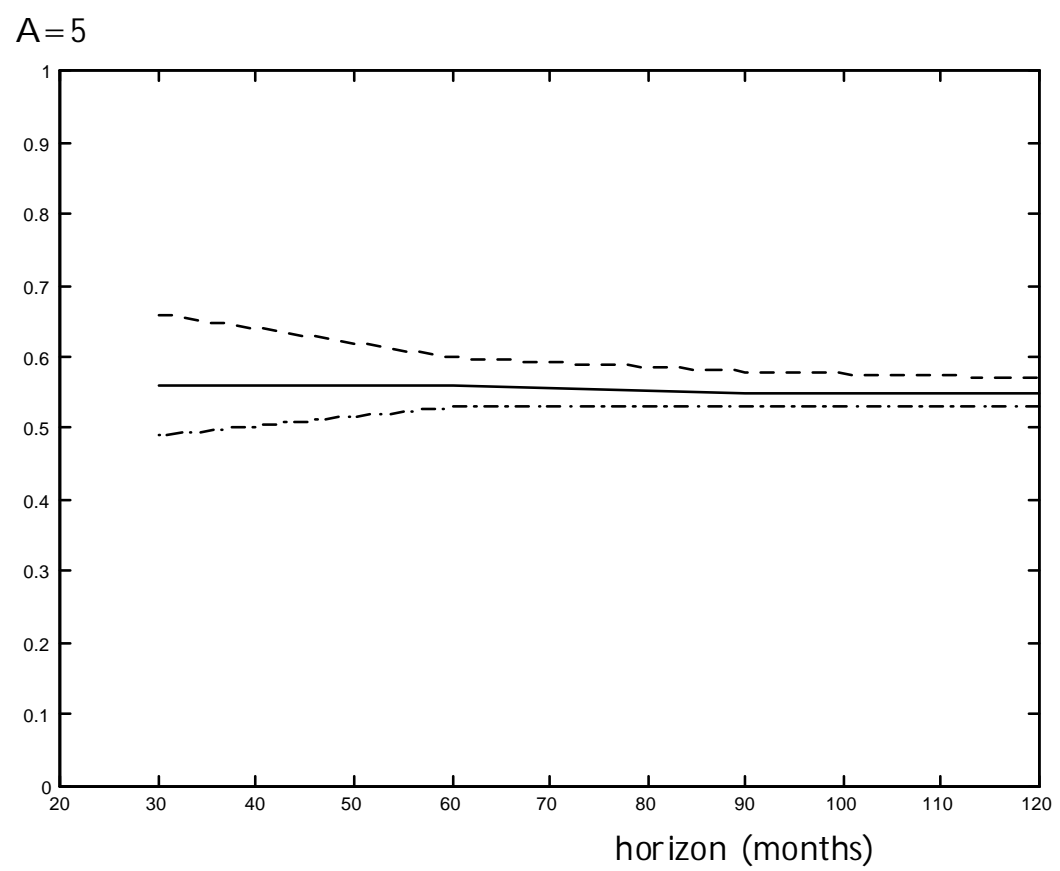

$A=10$

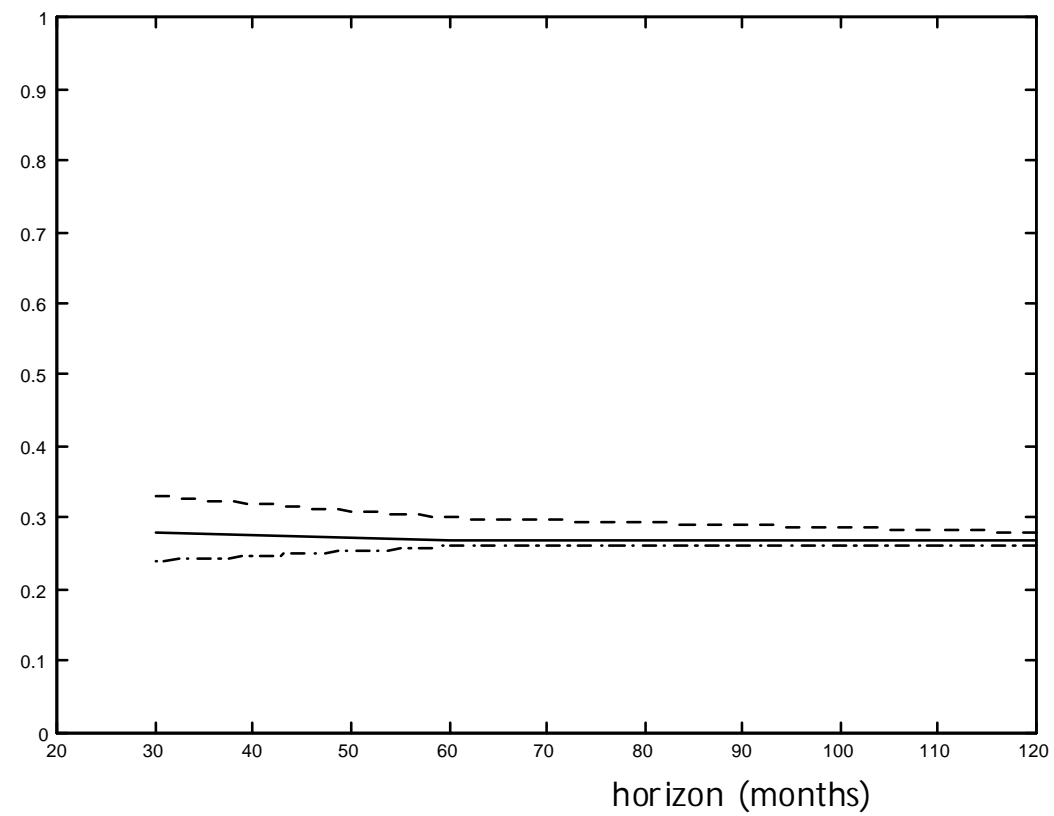

Figure 6. Allocation to bonds as a function of the investment horizon and the term spread. The graph plots for dixerent horizons the allocation to 10-year bonds in the absence of stocks when returns are assumed to be generated by a VAR model with four predictors. The initial values of the term spread are 0.09 (dash-dot line), 0.69 (solid line), and 1.39 (dash line). In every graph, the joitial values for the rest of variables are their sample means. 


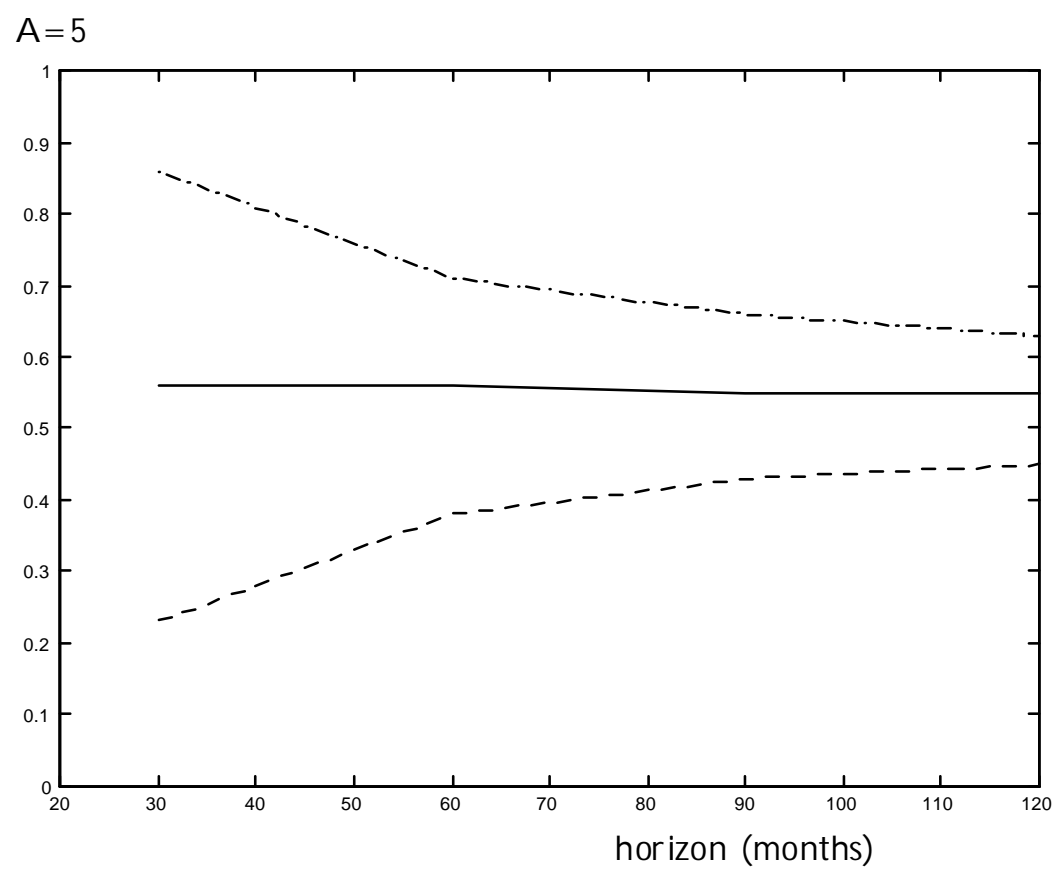

$A=10$

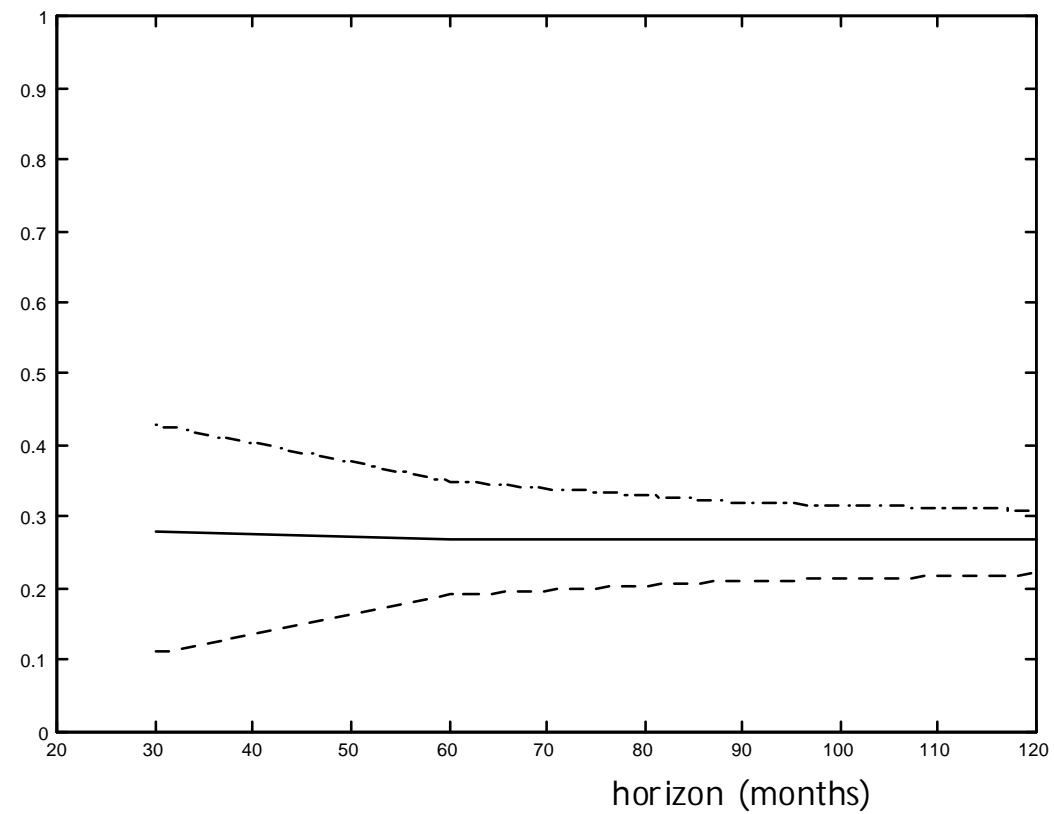

Figure 7. Allocation to bonds as a function of the investment horizon and the trend. The graph plots for dixerent horizons the allocation to 10-year bonds in the absence of stocks when returns are assumed to be generated by a VAR model with four predictors. The initial values of the term spread are - 0.7 (dash-dot line), 1.71 (solid line), and 4.5 (dash line). In every graph, the initial values for the rest of bariables are their sample means. 


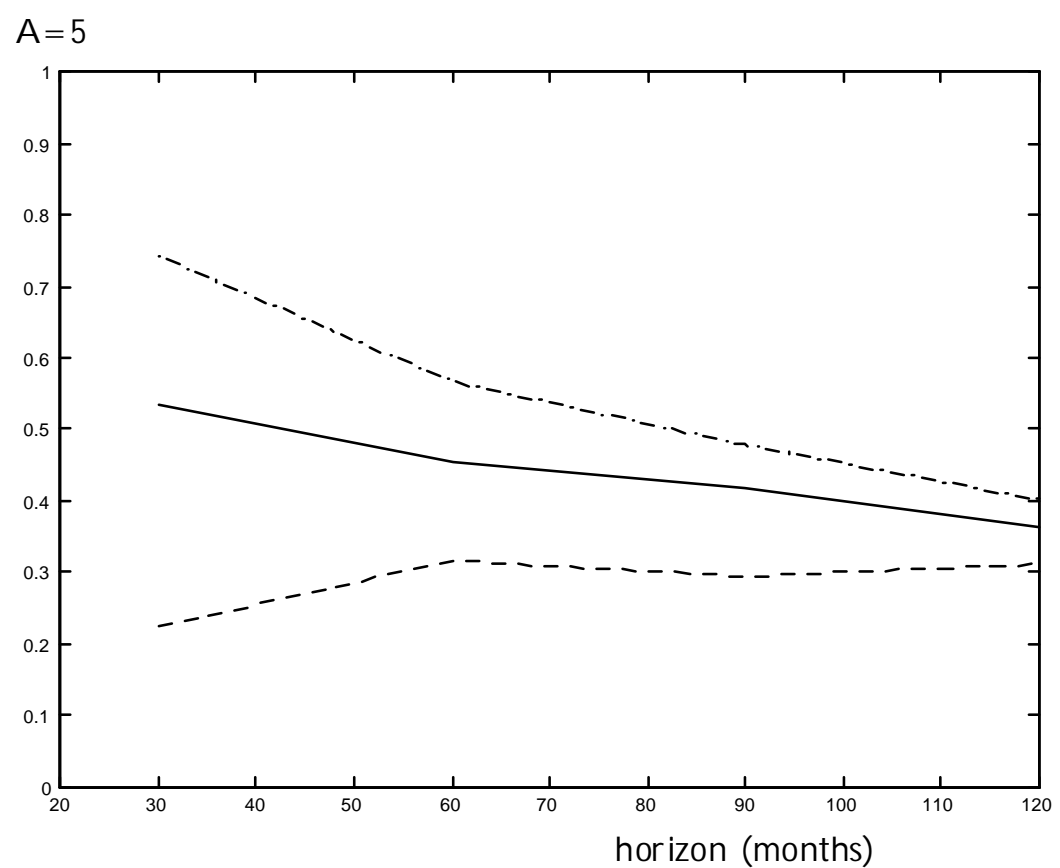

$A=10$

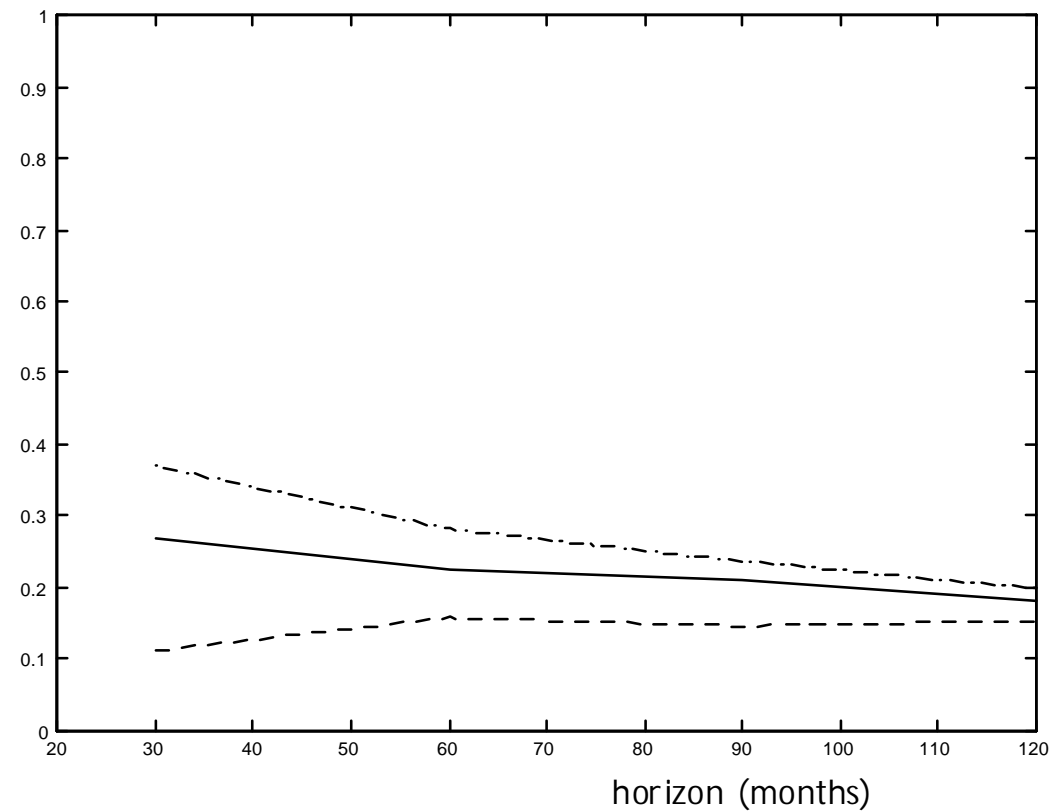

Figure 8. Allocation to bonds as a function of the investment horizon and the trend under parameter uncertainty. The graph plots for dixerent horizons the allocation to 10-year bonds in the absence of stocks when returns are assumed to be generated by a VAR model with four predictors. The initial values of the term spread are -0.7 (dash-dot line), 1.71 (solid line), and 4.5 (dash lizze). In every graph, the initial values for the rest of variables are their sample means. The invest or takes estimation risk into account. 


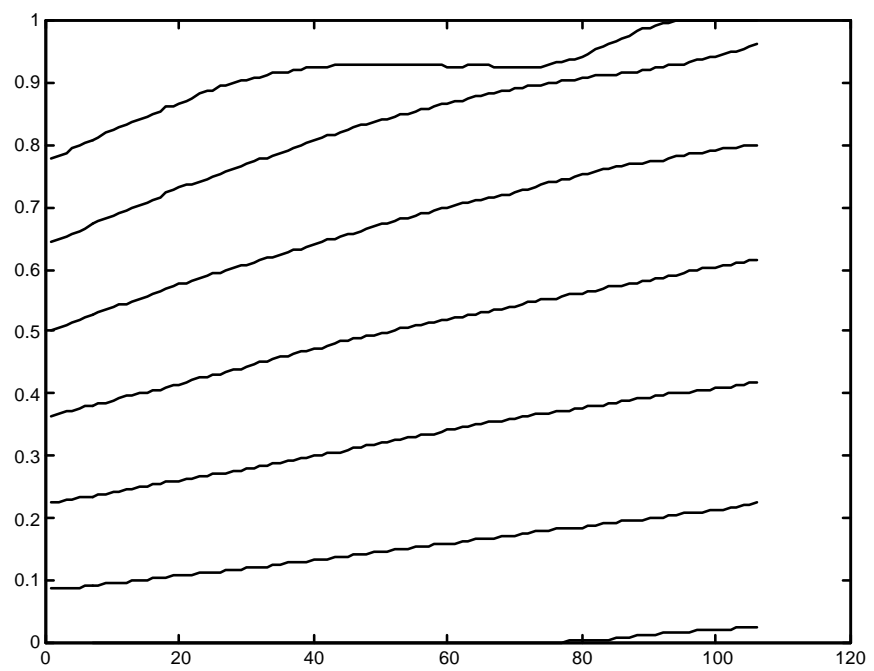

Long-Term Bonds

horizon (months)

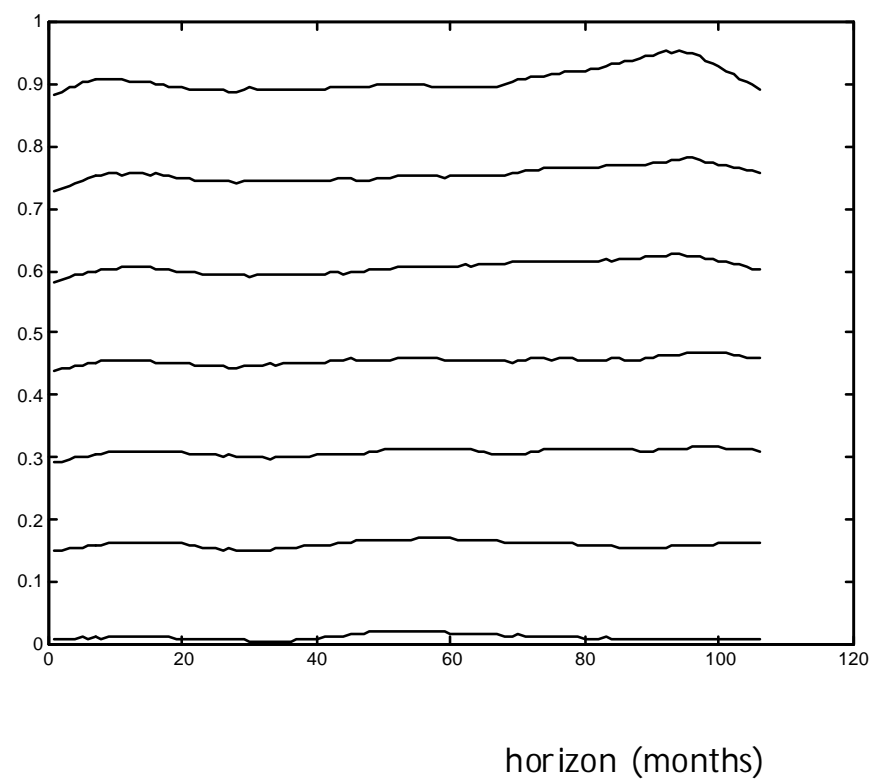

Figure 9. Dynamic allocation to stocks and bonds as a function of the investment horizon, and the dividend yield and trend respectively. The top graph plots for dixer ent horizons the allocation to stocks when returns are assumed to be predicted by the dividend yield. The initial values of the dividend yield equal 1, 2, 7 (from bottom to top). The bottom graph plots for dixesent horizons the allocation to stocks when returns are assumed to be predicted by the trend. The initial values of the trend equal $-2,-1$, 3 (from top to bottom). 


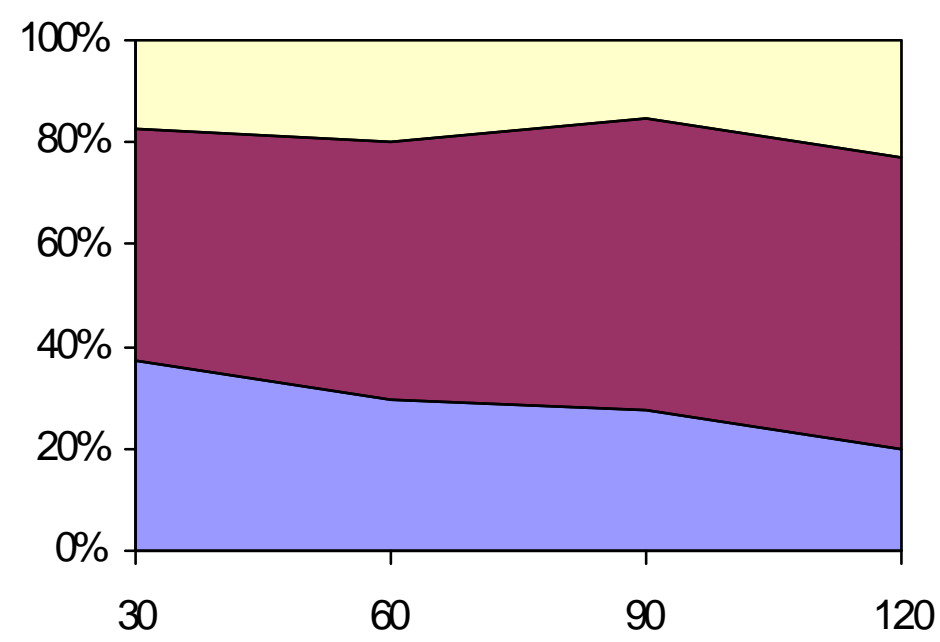

horizon (months)

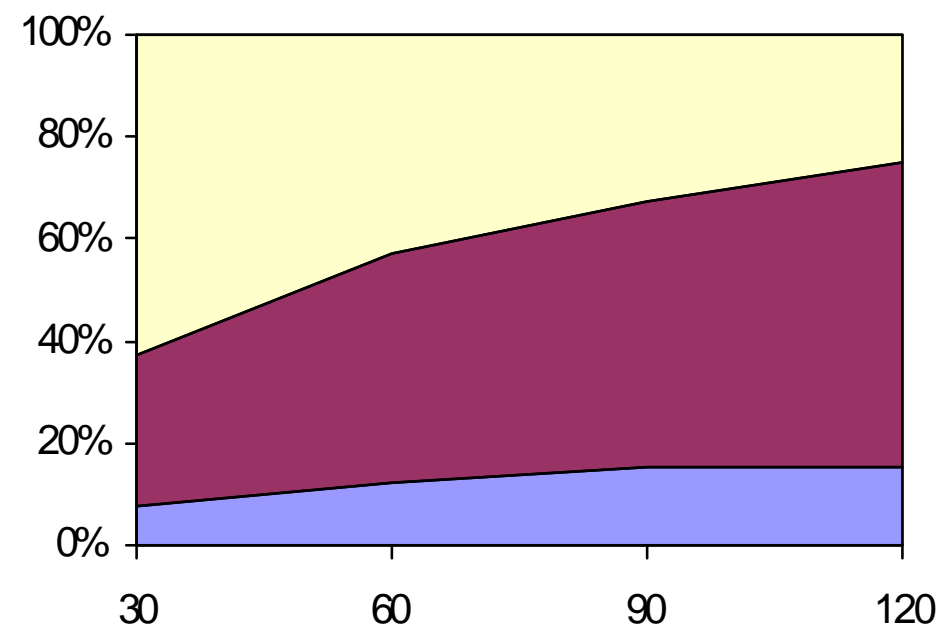

horizon (months)

Figure 10. Allocation to bonds and stocks for dixerent initial values of trend. The graph plots the static allocation to the riskless asset (light shade) 10-year bonds (medium shade) and stocks (dark shade) for dixerent horizons when returns are assumed to be generated by a VAR model with four predictors. The initial values of trend are - 0.7 (upper graph) and 4.5 (lower graph). The rest of initial variables are initially at thair mean levels. The investor does not take parameter uncertainty into account. The risk aversion coec cient is 10 . 


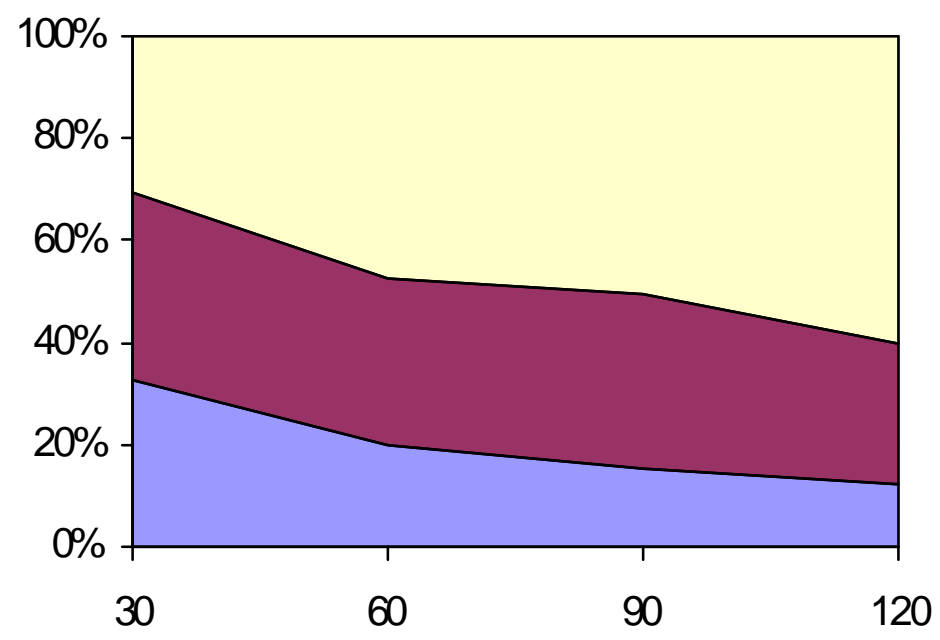

horizon (months)

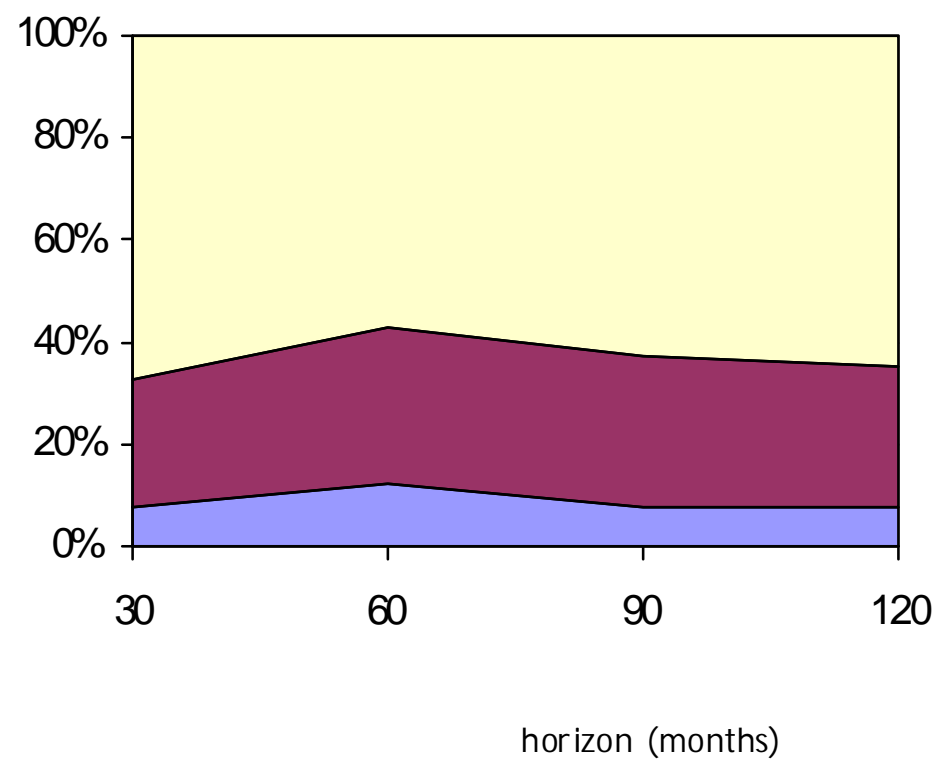

Figure 11. Allocation to bonds and stocks for dixerent initial values of trend under parameter uncertainty. The graph plots the static allocation to the riskless asset (light shade) 10-year bonds (medium shade) and stocks (dark shade) for dixerent horizons when returns are assumed to be generated by a VAR model with four predictors. The initial values of trend are -0.7 (upper graph) and 4.5 (lower graph). The rest of vasjables are initially at their mean levels. The investor takes parameter uncert ainty into account. The risk aversion coeф cient is 10 . 

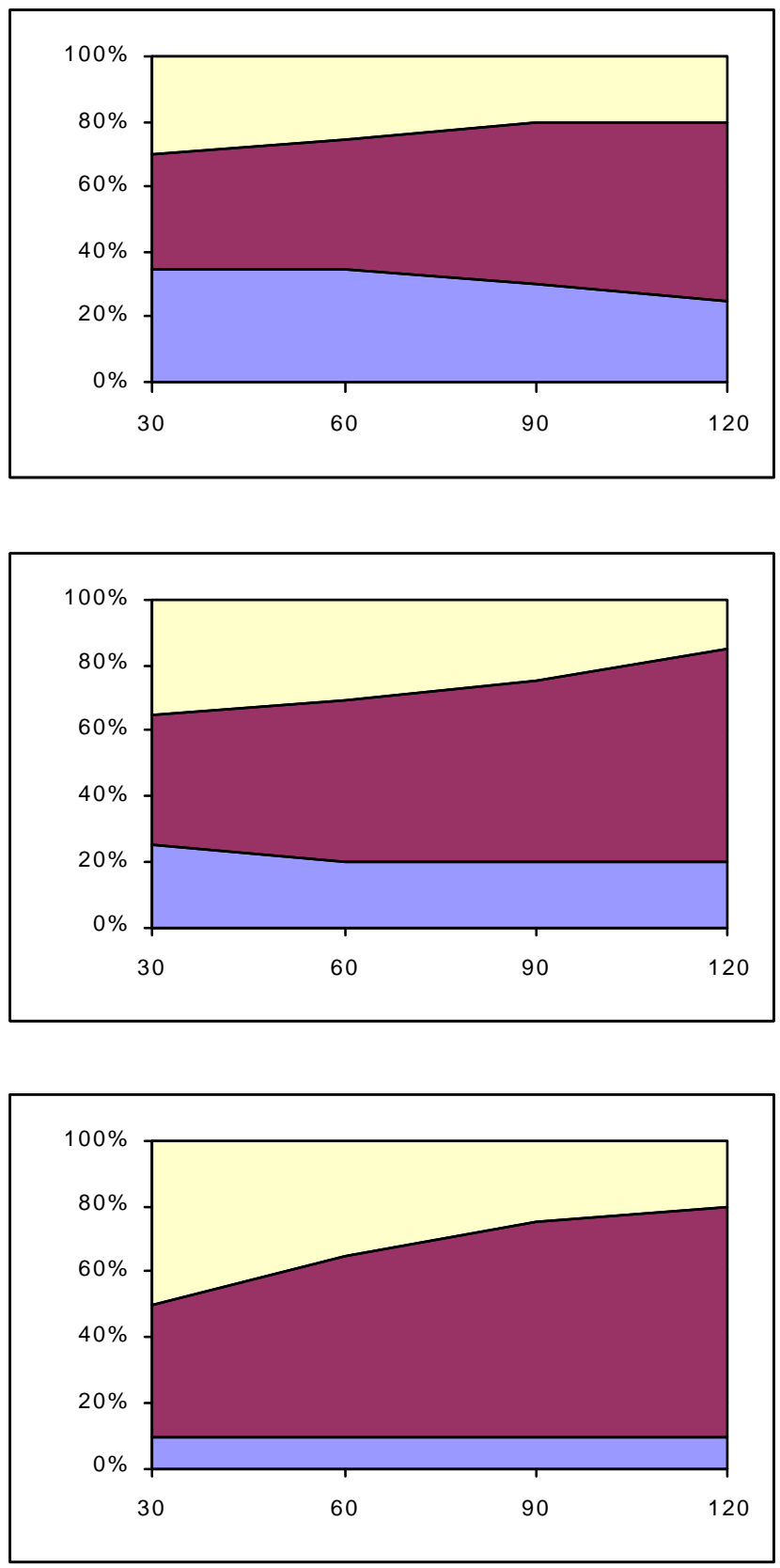

horizon (months)

Figure 12. Allocation to bonds and stocks for dixerent initial values of dividend yield. The graph plots the static allocation to the riskless asset (light shade) 10-year bonds (medium shade) and stocks (dark shade) for dixerent horizons when returns are assumed to be generated by a VAR model with four predictors. The initial values of DP are 2.88 (upper graph) 3.44 (middle graph) and 4.07 (lo36er graph). The rest of variables are initially at their mean levels. The investor does not take parameter uncertainty into account. The risk aversion coeф cient is 10 . 

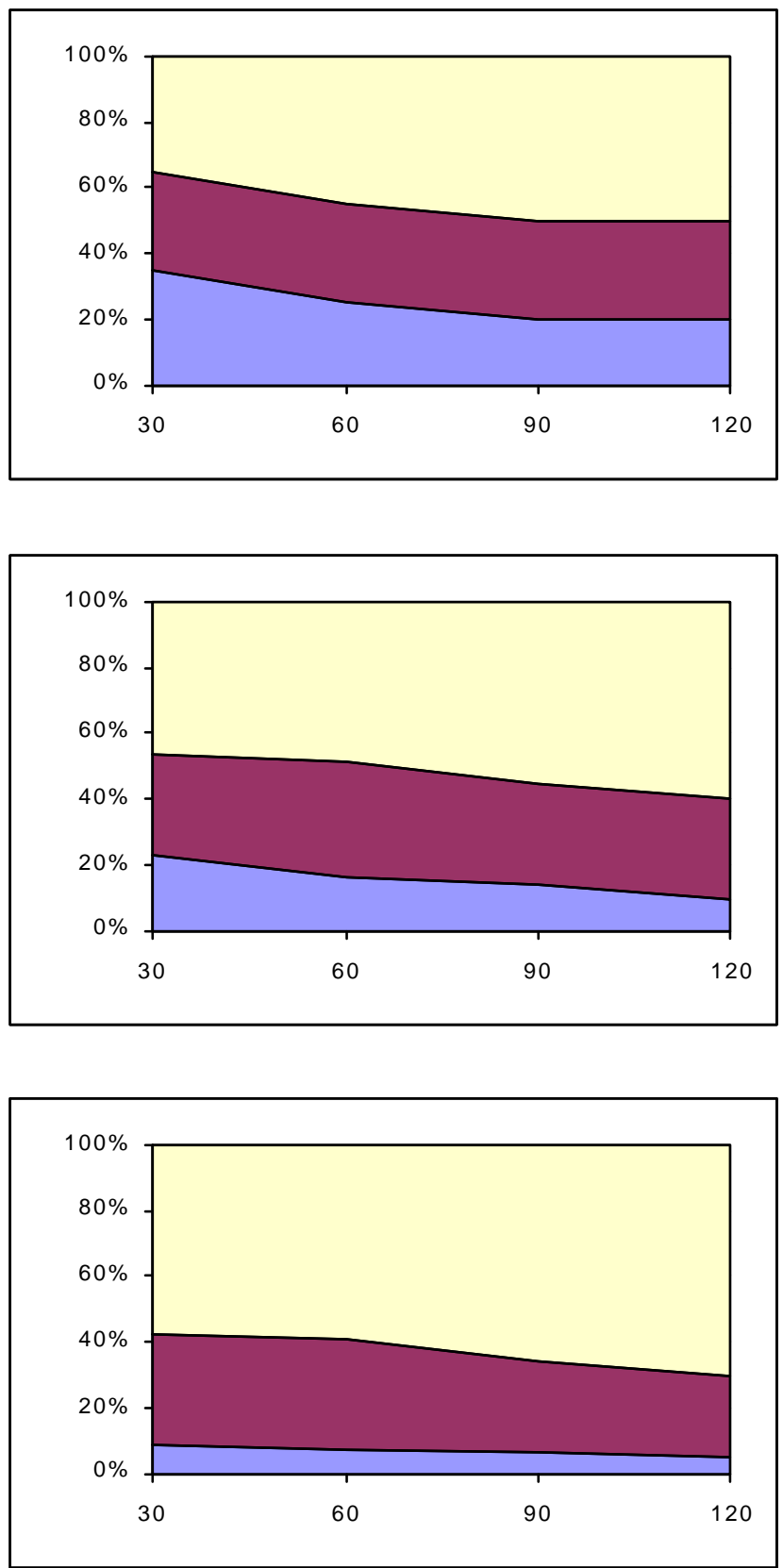

horizon (months)

Figure 13. Allocation to bonds and stocks for dixerent initial values of dividend yield under parameter uncertainty. The graph plots the optimal allocation to the riskless asset (light shade) 10-year bonds (medium shade) and stocks (dark shade) for dixerent horizons when returns are assumed to be gener ated by a VAR model with four predictors. The initial values of DP are 2.88 (upper graph) $3 . \$ 7$ (middle graph) and 4.07 (lower graph). The rest of variables are initially at their mean levels. The investor takes parameter uncertainty into account. The risk aversion coet cient is 10. 


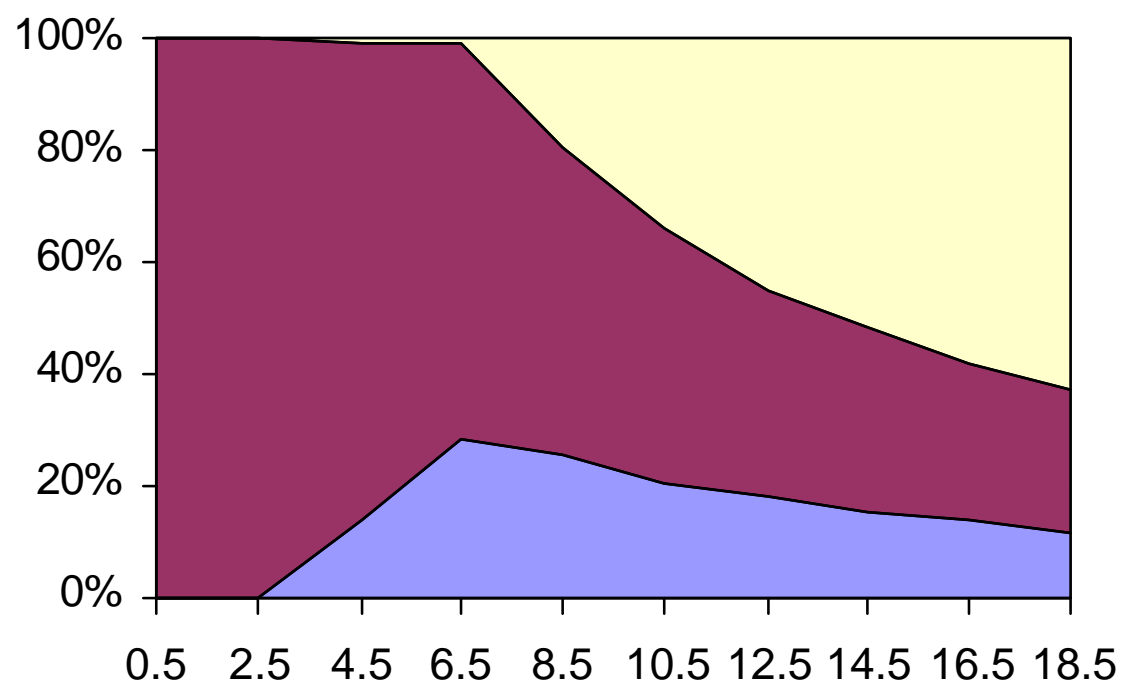

Risk aversion coec cient

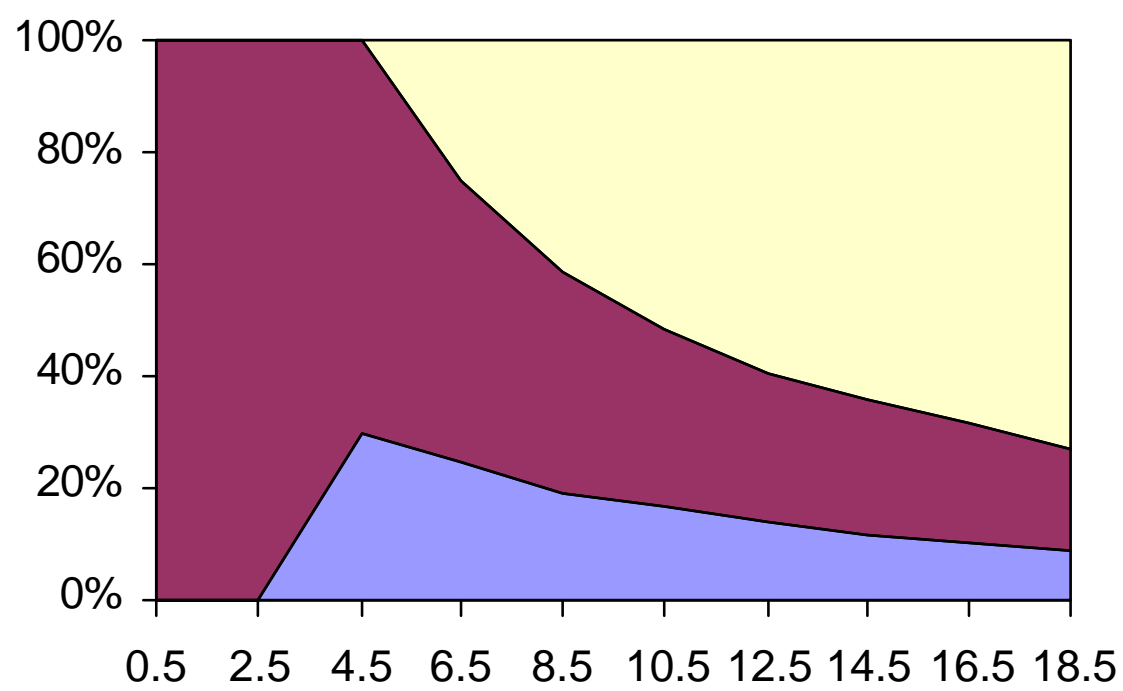

Risk aversion coec cient

Figure 14. Portfolio choice and risk aversion. The graphs plot the optimal allocation to the riskless asset (lighi shade), 10-year bonds (medium shade) and stocks (dark shade) for a 5 year investment horizon and when predictors are initially at their sample means. 